Article

\title{
Study on the Aging Resistance of Polyurethane Precursor Modified Bitumen and its Mechanism
}

\author{
Liang Zhang ${ }^{1}$, Pengfei $\mathrm{Li}^{2}$, Guanfeng Hu ${ }^{3}$, Sufeng Zhang ${ }^{1}$, Bin Hong ${ }^{4, *}$, Haopeng Wang ${ }^{5, *}$, Dawei Wang ${ }^{4,6}(\mathbb{C}$ \\ and Markus Oeser ${ }^{6}$
}

1 Heilongiiang Highway Construction Center, Harbin 150040, China; 20S132085@stu.hit.edu.cn (L.Z.); 20S032028@stu.hit.edu.cn (S.Z.)

2 Highway Engineering Cost Station of Heilongjiang Province, Harbin 150008, China; 19B932019@stu.hit.edu.cn

3 Heilongiiang Longiian Road bridge 5th Engineering Co., Ltd., Harbin 150077, China; 20B932028@stu.hit.edu.cn

4 School of Transportation Science and Engineering, Harbin Institute of Technology, Harbin 150090, China; wang@isac.rwth-aachen.de

5 Section of Pavement Engineering, Faculty of Civil Engineering \& Geosciences, Delft University of Technology, $2628 C N$ Delft, The Netherlands

6 Institute of Highway Engineering, RWTH Aachen University, 52074 Aachen, Germany; oeser@isac.rwth-aachen.de

* $\quad$ Correspondence: binhong@hit.edu.cn (B.H.); haopeng.wang@tudelft.nl (H.W.); Tel.: +86-451-8628-2840 (B.H.); +31 6253-61801 (H.W.)

Citation: Zhang, L.; Li, P.; Hu, G.; Zhang, S.; Hong, B.; Wang, H.;

Wang, D.; Oeser, M. Study on the

Aging Resistance of Polyurethane Precursor Modified Bitumen and its Mechanism. Sustainability 2021, 13, 9520. https://doi.org/10.3390/ su13179520

Academic Editor: Antonio D'Andrea

Received: 28 June 2021

Accepted: 18 August 2021

Published: 24 August 2021

Publisher's Note: MDPI stays neutral with regard to jurisdictional claims in published maps and institutional affiliations.

Copyright: (c) 2021 by the authors. Licensee MDPI, Basel, Switzerland. This article is an open access article distributed under the terms and conditions of the Creative Commons Attribution (CC BY) license (https:// creativecommons.org/licenses/by/ $4.0 /)$.

\begin{abstract}
As an environmentally friendly alternative for the production of high-performance modified asphalt by chemical reactions, a liquid-state polyurethane-precursor-based reactive modifier (PRM) was developed and employed in the asphalt modification. In contrast to the traditional solid bitumen modifier, for example, rubber and thermoplastic elastomers, the PRM as a liquid modifier has more significant advantages in reducing energy consumption and improving asphalt performance, which has attracted widespread attention. However, the aging resistance and its mechanism are not clear. In view of this, the aging performance of two PRM-modified bitumen (PRM-70 and PRM-90), under the short-term thermo-oxidative aging, long-term thermo-oxidative aging, and ultraviolet (UV) aging conditions, was investigated through chemical and mechanical methods. The results show that the PRM-90 is more susceptible to the thermos-oxidative aging and UV aging. The use of low-penetration-grade bitumen and ensuring an adequate reaction are beneficial to enhance the aging resistance of PRM-modified bitumen. The impact of aging on high-temperature performance of PRM-modified bitumen is great, followed by the low-temperature performance and the anti-fatigue performance. The mechanic-relevant rheological aging index $(R A I)$ and fracture energy index (FEI) are recommended to evaluate aging properties for PRM-modified bitumen. This study not only provides support for further research on the relationship between the aging properties and mechanical performance of PRM-modified bitumen, but also provides a reference for conducting mechanism analysis.
\end{abstract}

Keywords: polyurethane precursor; modified bitumen; aging resistance; thermal-oxidation aging; ultraviolet aging

\section{Introduction}

With the increased environmental concerns and traffic demands in pavement construction, the liquid-based polyurethane-precursor-based reactive modifier (PRM) was developed as an eco-friendly approach to improve the high-temperature performance of bitumen, which demonstrates dual values in environmental protection and performance improvement of pavement [1,2]. Due to the wide presence of free radicals in asphalt binders, the covalent crosslinking network structure is expected to be established by the reactions of active sites in asphalt and isocyanate groups in PRM. PRM as a liquid-state 
chemical modifier makes the preparation process of modified bitumen simple, more convenient, and reduces the equipment cost. Moreover, a lower energy consumption in the preparation process can be obtained due to the advantages of liquid-liquid blending, which can reduce the production temperature to $140-150{ }^{\circ} \mathrm{C}$. On the other hand, the decreasing of the production temperature can also reduce the base bitumen damage caused by high temperature. Therefore, PRM is an ideal, ecological, and economically viable chemical modifier for bitumen.

However, bitumen aging is regarded as a critical factor that leads to the degradation of pavement performance and severely shortens the service life of asphalt pavement $[3,4]$. The aging resistance of PRM-modified bitumen has not been fully expounded, which still need to be further investigated.

As the bonding material in mixture, the bitumen is usually characterized using relative quantities of saturate, aromatic, resin, and asphaltene (SARA) fractions [5]. Due to the complex composition of bitumen, there will be inevitable bitumen aging accrued during storage, mixing, transport, and laying down as well as in service life under the comprehensive effects of heat, oxygen, and ultraviolet (UV) irradiation and traffic activities [6-9]. It is commonly regarded that bitumen aging is closely related to oxidation, loss of volatile components, and exudation of oily components from bitumen into the aggregate [10-13]. Aging effects can be represented by the irreversible mobility of the light components into resins and asphaltenes using the analysis of SARA fractions [14-16]. Those transfers eventually lead to the physical hardening and stiffing of bitumen with aging time increasing $[17,18]$. Consequently, the physical and rheological properties of bitumen will change depending on the aging degree. The most common result is the penetration and ductility decrease while the softening point and viscosity increase. Specifically, the aging behavior is dependent on the characteristics of bitumen, mixing conditions of the binder, and environmental conditions of the asphalt pavement [16]. Therefore, bitumen aging is a comprehensive and complex process.

As the same with bio-oil-modified bitumen [19], obviously aging also accrues in PRM-modified bitumen, which significantly affects the performance of bitumen. The aging process of PRM-modified bitumen becomes more complex due to the presence of reactive functional groups presented in the bitumen. Meanwhile, the aging behaviors of PRM-modified bitumen before and after aging is influenced by both base bitumen and the PRM modifier. Thus, it is of great significance to characterize the aging properties and explain the modification mechanism of the material for expanding its application.

The objective of this study is to investigate the thermo-oxidative and UV aging behavior of PRM-modified bitumen made from two base bitumen by the different methods of the rolling thin film oven test (RTFOT), the pressure aging vessel (PAV), and UV irradiation. Analysis of physical and rheological properties of PRM-modified bitumen before and after aging was carried out. In addition, the aging mechanism was analyzed from the sight of the energy varying and chemical structure by using the differential scanning calorimeter (DSC) and Fourier-transform infrared (FTIR) tests.

\section{Materials and Methods}

\subsection{Materials}

The bitumen Liaohe-70 (LH-70) and Liaohe-90 (LH-90), separately having 60/80 and $80 / 100$ penetration grades, were used as base bitumen in this study. The main physical properties of the two base bitumen are illustrated in Table 1. 
Table 1. Physical properties of the base bitumen and PRM-modified bitumen.

\begin{tabular}{|c|c|c|c|c|c|}
\hline \multirow{2}{*}{ Physical Properties } & \multicolumn{4}{|c|}{ Measured Values } & \multirow{2}{*}{ Method } \\
\hline & LH-70 & LH-90 & LH-70 +2.5\% & LH-90 +2.5\% & \\
\hline Penetration @25 ㄷ $\mathrm{C}(0.1 \mathrm{~mm})$ & 61.2 & 81.2 & 35.1 & 46.9 & T 0604-2011 \\
\hline Softening point $\left({ }^{\circ} \mathrm{C}\right)$ & 49.0 & 46.4 & 55.7 & 53.6 & Т 0606-2011 \\
\hline Ductility @ $5^{\circ} \mathrm{C}$ and $1 \mathrm{~cm} / \mathrm{min}(\mathrm{cm})$ & 92.7 & 141.0 & 6.4 & 11.1 & Т 0605-2011 \\
\hline Brookfield viscosity @135 ${ }^{\circ} \mathrm{C}(\mathrm{Pa} \cdot \mathrm{s})$ & 0.287 & 0.279 & 0.607 & 0.544 & Т 0625-2011 \\
\hline Brookfield viscosity @175 ${ }^{\circ} \mathrm{C}(\mathrm{Pa} \cdot \mathrm{s})$ & 0.084 & 0.065 & 0.165 & 0.129 & T 0625-2011 \\
\hline
\end{tabular}

The polyurethane-precursor-based reactive modifier containing isocyanate functional groups (PRM) was obtained and employed to prepare PRM-modified bitumen.

\subsection{Preparation of PRM-Modified Bitumen}

The modified bitumen was prepared using a high shear mixer (HSM-100L) manufactured by ROSS Equipment Co., Ltd. Approximately $850 \mathrm{~g}$ of base bitumen was poured into a metal container, then it was heated up to the blending temperature of $145^{\circ} \mathrm{C}$. The PRM modifier was added to bitumen within $20 \mathrm{~min}$ afterwards and then sheared at $3000 \mathrm{r} / \mathrm{min}$ for $2 \mathrm{~h}$. The typical weight percentage of $2.5 \%$ of PRM modifiers were employed.

\subsection{Aging Methods}

Aging of PRM-modified bitumen was carried out through short-term aging, long-term aging, and ultraviolet (UV) aging according to the JTG025-2000 Standard Test Methods of Bitumen and Bituminous Mixtures for Highway Engineering. Short-term aging of the PRM-modified bitumen was performed by the rolling thin film oven test (RTFOT). The standard test method is conducted at $163{ }^{\circ} \mathrm{C}$ for $85 \mathrm{~min}$ with continuous hot air being injected into the rotating sample bottles at the flow rate of $4000 \mathrm{~mL} / \mathrm{min}$, in order to simulate the degradation of bitumen that occurs during the hot-mix process. Following short-term aging, each RTFOT-aged sample was further aged in a Pressure Aging Vessel $(\mathrm{PAV})$ machine at a temperature of around $100{ }^{\circ} \mathrm{C}$ under $2.1 \mathrm{MPa}$ air pressure for $20 \mathrm{~h}$ to simulate long-term aging.

The Ultraviolet (UV) aging test was conducted in the ultraviolet radiation oven with eight ultraviolet lamps at $60^{\circ} \mathrm{C}$ and lasted for 5 days. The ultraviolet lamps (UVA-340) were manufactured by the Q-Lab Corporation (USA) and the power of each is $40 \mathrm{~W}$. An amount of $14.2 \mathrm{~g}$ melted bitumen was poured into a culture dish with a diameter of $77.5 \mathrm{~mm}$. The thickness of the bitumen film was about $3 \mathrm{~mm}$. The average UV intensity on the bitumen surface was about $2650 \mathrm{uW} / \mathrm{cm}^{2}$. Through the continuous monitoring of UV intensity for 5 days from 5:00 to 17:00 in September, the average UV intensity in Harbin (China) is $793 \mathrm{uW} / \mathrm{cm}^{2}$. The UV test conducted in this research lasted for 5 days ( $16 \mathrm{~h}$ of light, $8 \mathrm{~h}$ of darkness), which is equivalent to 22 days of natural light radiation in Harbin. Specifically, in order to eliminate the interference between the thermal-oxidation aging and UV aging, the samples for UV test were not subject to RTFOT aging before.

\subsection{Chemical Characterization}

\subsubsection{Fourier-Transform Infrared (FTIR) Analysis}

Functional groups are responsible for the characteristic of the materials in the chemical reaction, which can be determined by infrared absorption under special wave number ranges using an infrared spectrometer $[20,21]$. In this approach, the infrared spectrum of PRM-modified bitumen was obtained by using Nicolet is50 Fourier-transform infrared (FTIR) spectroscopy through the attenuated total reflection (ATR) mode. The test spectrum ranges from $4000 \mathrm{~cm}^{-1}$ to $500 \mathrm{~cm}^{-1}$. 


\subsubsection{Differential Scanning Calorimeter (DSC) Analyses}

The differential scanning calorimeter (DSC) test is a kind of thermo analytical method that was developed to determine the physical changes of samples associated with a heat exchange under a controlled temperature [22,23]. Planche et al. [24] have shown that the glass transition temperature $\left(T_{\mathrm{g}}\right)$ is one of the important properties that are especially relevant for the physical hardening. In addition, the $T_{\mathrm{g}}$ temperature obtained from the heating scans are more repeatable and easier to obtain in comparison to the cooling scans [23]. The $T_{\mathrm{g}}$ of PRM-modified bitumen pre- and post-aging was determined by using the NETZSCH 200F3 DSC manufactured in Germany.

After being sealed in the aluminum crucible, the bitumen sample was placed in the DSC apparatus and conditioned at $20^{\circ} \mathrm{C}$ for $5 \mathrm{~min}$. Then it was heated from $20{ }^{\circ} \mathrm{C}$ to $140{ }^{\circ} \mathrm{C}$ at $10^{\circ} \mathrm{C} / \mathrm{min}$ where it was left for $10 \mathrm{~min}$ isotherm at a high temperature, followed by the cooling process from $140{ }^{\circ} \mathrm{C}$ down to $-100{ }^{\circ} \mathrm{C}$ at $-10^{\circ} \mathrm{C} / \mathrm{min}$. After this cooling process, the sample was left another $10 \mathrm{~min}$ isothermally at $-100{ }^{\circ} \mathrm{C}$, followed by the measurement of $T_{\mathrm{g}}$ temperature from the low temperature of $-100{ }^{\circ} \mathrm{C}$ to $100{ }^{\circ} \mathrm{C}$ at a heating rate of $10^{\circ} \mathrm{C} / \mathrm{min}$. The sample was left for $3 \mathrm{~min}$ isothermally then cooled to the terminal temperature of $20^{\circ} \mathrm{C}$ at $-20^{\circ} \mathrm{C} / \mathrm{min}$.

\subsection{Mechanical Properties}

\subsubsection{Physical Properties Tests}

The physical properties of base bitumen and PRM-modified bitumen, including the penetration $\left(25^{\circ} \mathrm{C}\right)$, softening point, and Brookfield viscosity were tested according to $\mathrm{T}$ 0604-2011, T 0606-2011, and T 0625-2011 specified by the Chinese specification of Standard Test Methods of Bitumen and Bituminous Mixtures for Highway Engineering (JTG E202011), respectively.

Based on the physical test, the aging indexes were utilized for the evaluation of aging susceptibility of PRM-modified bitumen. The aging indexes were calculated by using the test results of bitumen before and after aging. According to Equations (1)-(3), the semi-empirical aging index of the retained penetration ratio $(R P R)$, viscosity aging index $(V A I)$, and softening point increment $(S P I)$ of the aged bitumen were calculated as:

$$
\begin{gathered}
V A I=\frac{\text { Aged vicosity value }- \text { Unaged vicosity value }}{\text { Unaged vicosity value }} \times 100 \\
S P I=\text { Aged softening point value }- \text { Unaged softening point value } \\
R P R=\frac{\text { Aged penetration value }}{\text { Unaged penetration value }} \times 100
\end{gathered}
$$

\subsubsection{Rheological Properties Tests}

The viscoelastic behaviors of PRM-modified bitumen pre- and post-aging were measured by the ARES-G2 rotational rheometer made by TA Instruments, USA. A sinusoidal shearing load was applied on the bitumen. The complex shear modulus $\left(G^{*}\right)$ and the phase angle $(\delta)$ were obtained based on the mechanical response. In this research, all the DSR tests were conducted within the scope of linear viscoelastic (LVE) for the bitumen samples. Frequency sweeps were carried out over a range of $0.1-30 \mathrm{~Hz}$ at a series of specified temperatures $\left(12,24,36,48,60,72\right.$, and $\left.84^{\circ} \mathrm{C}\right)$. At intermediate test temperatures $\left(12,24\right.$, and $\left.36^{\circ} \mathrm{C}\right)$, the diameter of the parallel plates and the gap between two plates used were $8 \mathrm{~mm}$ and $2 \mathrm{~mm}$. At high temperature conditions $\left(48,60,72\right.$, and $\left.84^{\circ} \mathrm{C}\right)$, the diameter and gap used were $25 \mathrm{~mm}$ and $1 \mathrm{~mm}$, respectively. According to the time-temperature superposition principle, the results of the $G^{*}$ and $\delta$ obtained from frequency sweep test were then used for the construction of master curves at a reference temperature of $36^{\circ} \mathrm{C}$ based on the Williams-Landel-Ferry (WLF) equation. Temperature sweeps were employed to draw the isochronal plots over the temperature range from $12{ }^{\circ} \mathrm{C}$ to $84{ }^{\circ} \mathrm{C}$ at a shear frequency of $1.59 \mathrm{~Hz}$. 


\subsubsection{High-Temperature Properties Tests}

The multiple stress creep recovery (MSCR) test was used to evaluate the hightemperature performance of the binders. According to AASHTO T 350-14, the nonrecoverable creep compliance $(J n r)$ was calculated as a measure of the binder's contribution to the mixture, and the permanent deformation behavior and percent recovery $(R \%)$ reflects the elasticity of bitumen. The test was carried out at $60^{\circ} \mathrm{C}$, which is the highest work temperature of the asphalt pavement in most areas of China. During this test, the samples were subjected to two creep stress levels $(0.1 \mathrm{kPa}$ and $3.2 \mathrm{kPa})$ for $1 \mathrm{~s}$, followed by a recovery duration of $9 \mathrm{~s}$. A total of 10 loading recovery cycles were repeated for each test. For each type of binder, three samples were prepared for the MSCR test.

\subsubsection{Low-Temperature Properties Tests}

The low-temperature cracking resistance of bitumen is sensitive to the aging level. It has been reported that the single-edge notched bending (SENB) test can be used to distinguish the cracking resistance of different bitumen effectively $[25,26]$. By using the SENB device developed by the Harbin Institute of Technology, the fracture behaviors of aged and unaged bitumen were evaluated at $-12{ }^{\circ} \mathrm{C}$. During the SENB test, the loading rate at $0.05 \mathrm{~mm} / \mathrm{s}$ was applied on the center of the beam. The span length, $L$, is equal to $110 \mathrm{~mm}$ and the depth of pre-notch, $a$, is equal to $2.8 \mathrm{~mm}$. In the test, the displacement and load are recorded with time. The schematic diagram of SENB test is illustrated in Figure 1.

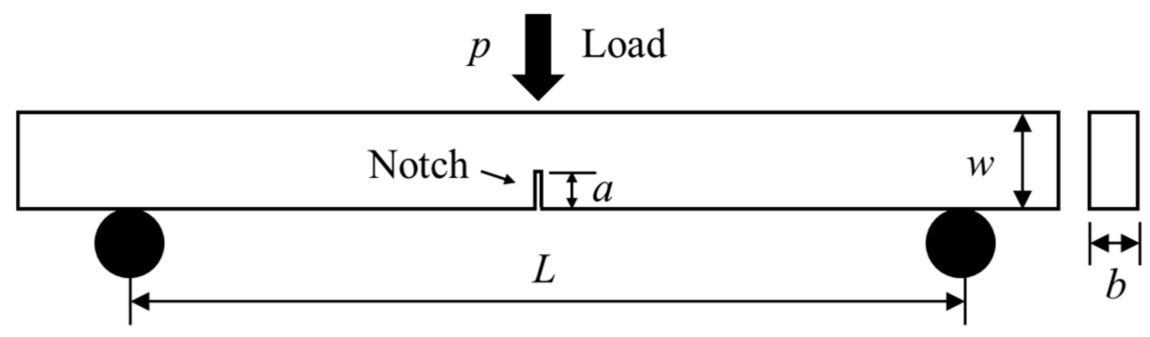

Figure 1. The illustration of the SENB test.

In this study, the fracture load and fracture energy $\left(G_{f}\right)$ were used for the evaluation of the fracture behaviors of bitumen. The $G_{f}$ is calculated as:

$$
G_{f}=\frac{W_{f}}{A_{\text {lig }}}
$$

where $W_{f}=\int p d u$ is the total area under the entire load-deflection curve and $A_{\text {lig }}=b(w-a)$ is the area of the ligament, $b$ is the width of sample.

\subsubsection{Fatigue Properties Tests}

Under current specifications, the $G^{*} \cdot \sin \delta$ is used to classify the fatigue performance of asphalt materials, which cannot effectively distinguish the fatigue resistance, especially for modified bitumen. In this regard, the linear amplitude sweep (LAS) test was proposed based on the viscoelastic continuum damage (VECD) method. The LAS test consists of two steps. The first step is the frequency sweep at a constant frequency of $0.1 \%$. The second step is the linear amplitude sweep. During this step, the amplitude of the sinusoidal load increases linearly from $0.1 \%$ to $30 \%$. According to the AASHTO TP 101 , the fatigue failure criterion of the materials is selected as the damage level reaches $35 \%$ of the initial value. In this research, the test was carried out at $25^{\circ} \mathrm{C}$. 


\section{Results and Discussions}

\subsection{Chemical Characterization}

\subsubsection{Functional Groups Analysis by FTIR}

The FTIR analysis of PRM-modified bitumen, including the bas bitumen, are plotted in Figure 2. It is noted that all base bitumen samples after UV aging failed, but this did not affect the result analysis. The chemical bonding of carbonyl $(\mathrm{C}=\mathrm{O})$ and sulphoxide $(\mathrm{S}=\mathrm{O})$ are commonly regarded as the critical indexes that can be used to characterize the degree of oxidative hardening or aging within organic compounds. The investigation of the related carbonyl bonding index $\left(I_{\mathrm{C}=\mathrm{O}}\right)$ and sulphoxide bonding index $\left(I_{\mathrm{S}=\mathrm{O}}\right)$ properties within the aged and unaged PRM-modified bitumen provides an effective way to reveal the aging behaviors of the PRM-modified bitumen on the molecular level. The research of Petersen et al. shown that the $\mathrm{S}=\mathrm{O}$ bond peak shows a trend of increasing first and then decreasing during oxidation [10]. As can be seen from the Figure 2, the carbonyl peak and sulphoxide peak already appeared at the unaged state of PRM-70 and PRM-90 binders, which was mainly attributed to the incorporation of modifier as well as the chemical modification between the polar groups of base bitumen and -NCO group of modifiers. Based on the FTIR spectra of the PRM bitumen, the quantitative calculation of $I_{\mathrm{C}=\mathrm{O}}$ and $I_{\mathrm{S}=\mathrm{O}}$ are conducted according to Equations (5) and (6).

$$
\begin{aligned}
& I_{\mathrm{C}=\mathrm{O}}=\frac{\text { Area of the carbonyl band around } 1700 \mathrm{~cm}^{-1}}{\text { Area of the spectral bands betweeen } 2000 \text { and } 600 \mathrm{~cm}^{-1}} \\
& I_{\mathrm{S}=\mathrm{O}}=\frac{\text { Area of the sulphoxide band around } 1030 \mathrm{~cm}^{-1}}{\text { Area of the spectral bands betweeen } 2000 \text { and } 600 \mathrm{~cm}^{-1}}
\end{aligned}
$$

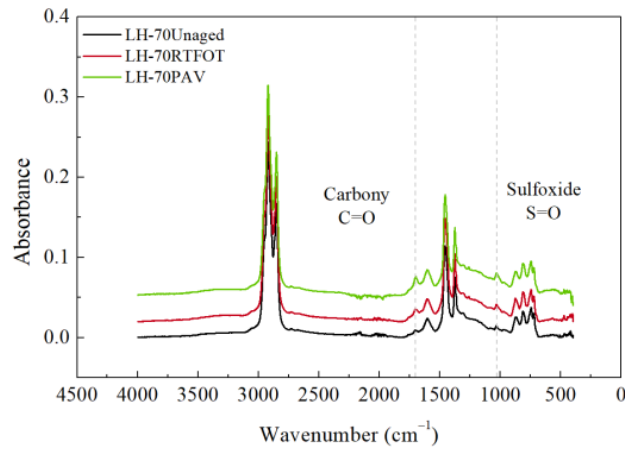

(a)

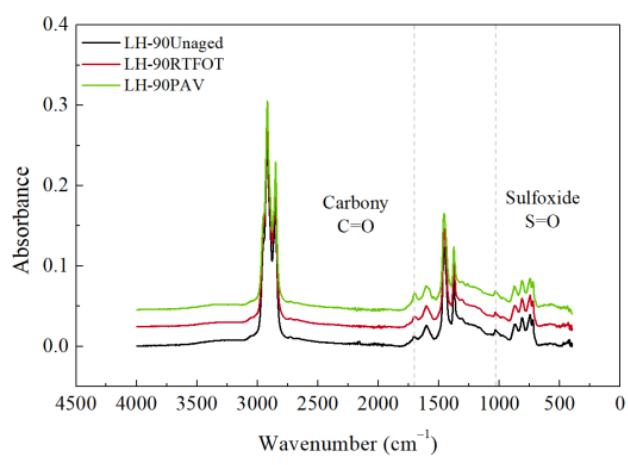

(c)

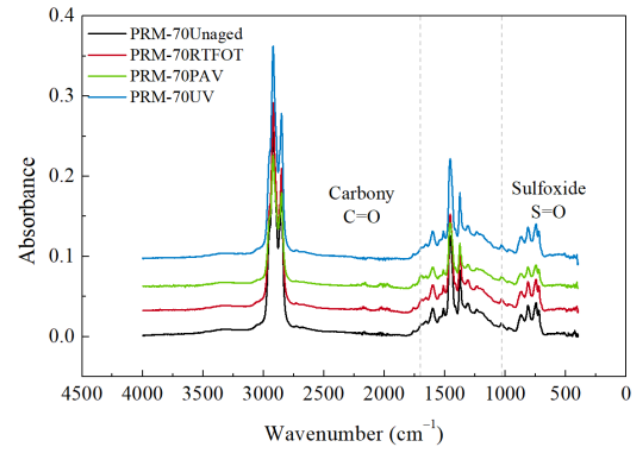

(b)

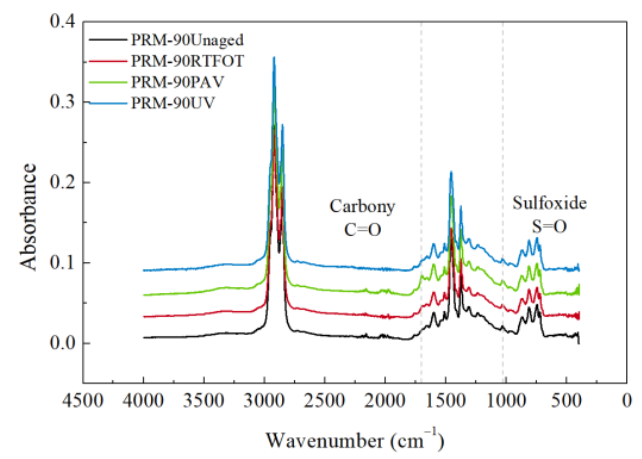

(d)

Figure 2. The FTIR spectra of bitumen: (a) LH-70 base bitumen, (b) PRM-70-modified bitumen, (c) LH-90 base bitumen, (d) PRM-90-modified bitumen. 
Figure 3 presents the chemical bonding indexes of $I_{\mathrm{C}=\mathrm{O}}$ and $I_{\mathrm{S}=\mathrm{O}}$ of the PRM-modified bitumen, including the base bitumen. The aged binders show visible increase in the bonding index of $I_{\mathrm{C}=\mathrm{O}}$, especially after the PAV aging. However, as for the bonding index of $I_{\mathrm{S}=\mathrm{O}}$, the aged binders show no visible increase. Only after the PAV aging can the distinct difference in $I_{\mathrm{S}=\mathrm{O}}$ be detected as compared to the unaged binder. Through the sum of chemical bonding indexes of $I_{\mathrm{C}=\mathrm{O}}$ and $I_{\mathrm{S}=\mathrm{O}}$, the chemical aging index $(C A I)$ was proposed to determine the difference in the binders in terms of their combined chemical susceptibility to aging. The CAI is expressed as Equation (7)

$$
C A I=\frac{I_{\mathrm{C}=\mathrm{O}, \text { aged }}+I_{\mathrm{S}=\mathrm{O}, \text { aged }}}{I_{\mathrm{C}=\mathrm{O}, \text { unaged }}+I_{\mathrm{S}=\mathrm{O}, \text { unaged }}}
$$

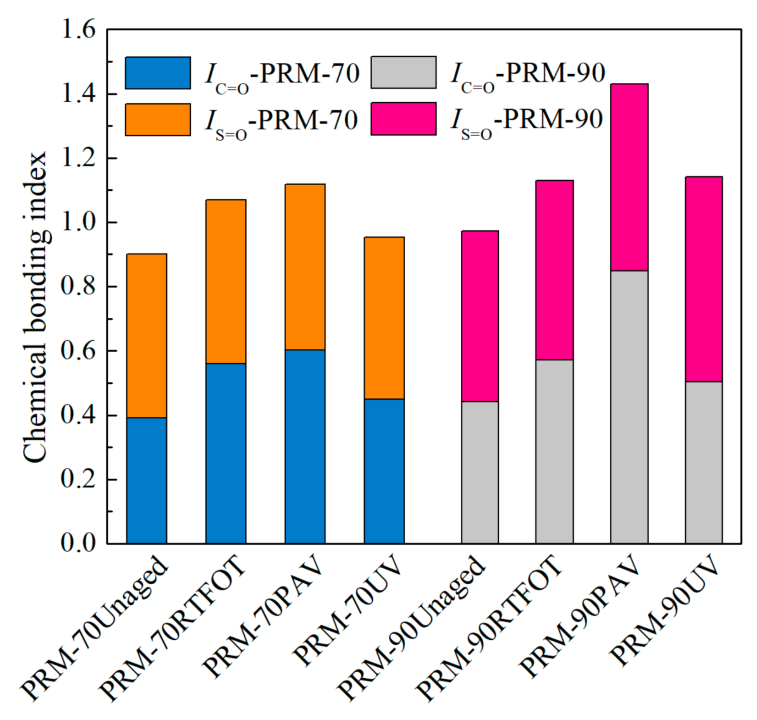

(a)

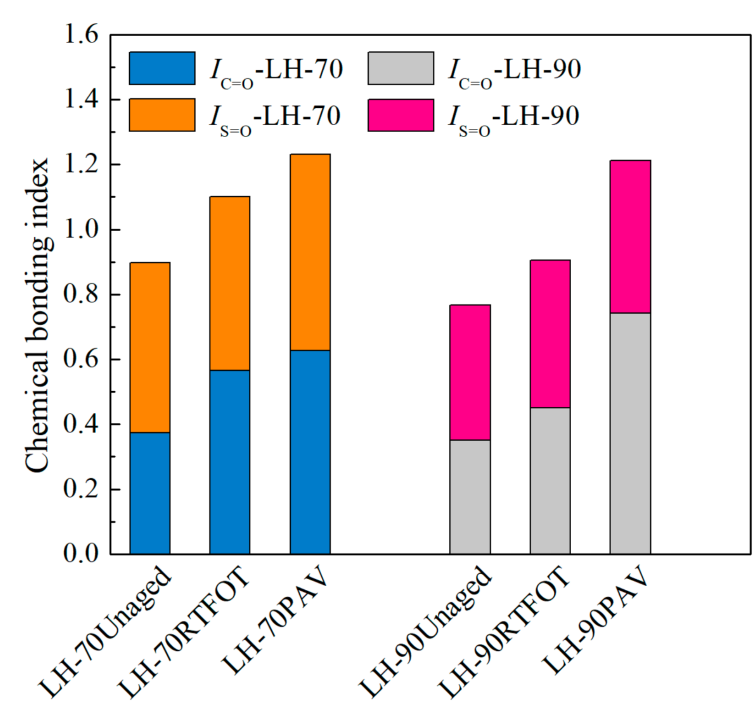

(b)

Figure 3. The chemical bonding of all the tested binders: (a) Base bitumen, (b) PRM-modified bitumen.

For the PRM-70 bitumen, the chemical aging index of the RTFOT-aged binder, the PAV-aged binder, and the UV-aged binder are $1.069,1.118$, and 0.954 , respectively. For the PRM-90 bitumen, the chemical aging index of the RTFOT-aged binder, the PAV-aged binder, and the UV-aged binder are 1.129, 1.429, and 1.141, respectively. The result of CAI indicated that the PRM-90 is more susceptible to short-term aging, long-term aging, and UV aging. This is due to the fact that the PRM-90-modified bitumen has more light fractions. It is subjected to more loss of volatiles and oxidation than the virgin PRM-70-modified bitumen that eventually leads to higher CAI. Besides, it is generally accepted that the asphaltenes have the strongest polarity in asphalt. Obviously, the LH-70 has more heavy components than LH-90, and a more sufficient reaction between asphalt molecules and PRM is expected to be obtained. The potential aging sites (such as phenols and benzyl alcohols) in LH-70 are expected to be reduced to a greater extent than LH-90 and thus the aging level of LH-70 is lower than LH-90.

\subsubsection{Physical Change Analysis by DSC}

Figure 4 shows a typical analysis on the glass transition temperature from the DSC curves. In terms of partially crystalline materials, the glass transition is regarded as a reversible transition of amorphous substances (or amorphous zones) from a hard, brittle (latent) state into a fused mass or a rubber-like state [27]. The glass transition temperature, also referred to as the midpoint temperature $\left(T_{\mathrm{g}}\right)$, was employed to evaluate the evolution of the aging state from the aspect of the chemical properties of bitumen. As shown in Figure 4 , the $T_{\mathrm{g}}$ values can be determined from a shift in the baseline of DSC curves. 


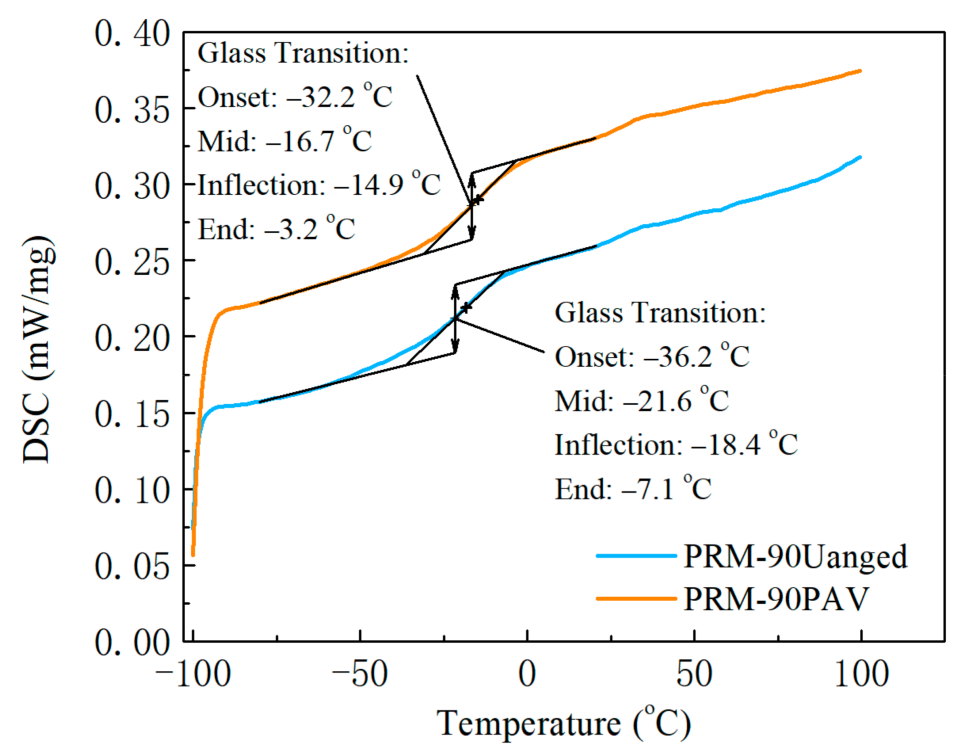

Figure 4. The illustration of the determination of glass transition point using the DSC curves.

The $T_{\mathrm{g}}$ results of all the investigated binders were plotted in Figure 5. It can be seen that the $T_{\mathrm{g}}$ values are reduced to a different degree after aging tests. Under the long-term and short-term impacts of thermal-oxidation aging, the volatilization of the light component, for example, saturates, and the transformation of the polar component (i.e., the aromatics and resins) to asphaltenes lead to the hardening of bitumen. Since the good fluidity and deformability of bitumen are desirable at low temperatures, the increase of $T_{\mathrm{g}}$ implies a reduction of the low-temperature performance of bitumen. In terms of the effect of UV aging on the $T_{\mathrm{g}}$ of PRM-70 and PRM-90 bitumen, the trend of the change is the same with the thermal-oxidation-aged samples. As a consequence of the irradiation of the ultraviolet spectrum, the molecules of certain substances in the bitumen may absorb the energies. The chemical bonds may be stimulated from the ground state to the active state, leading to the breaking of chemical bonds. Through the combination of hydrogen bonds between the polar functional groups, the components with a relatively low molecular weight in bitumen are transformed into components with a relatively high molecular weight. This mechanism leads to the increase of the glass transition temperature.

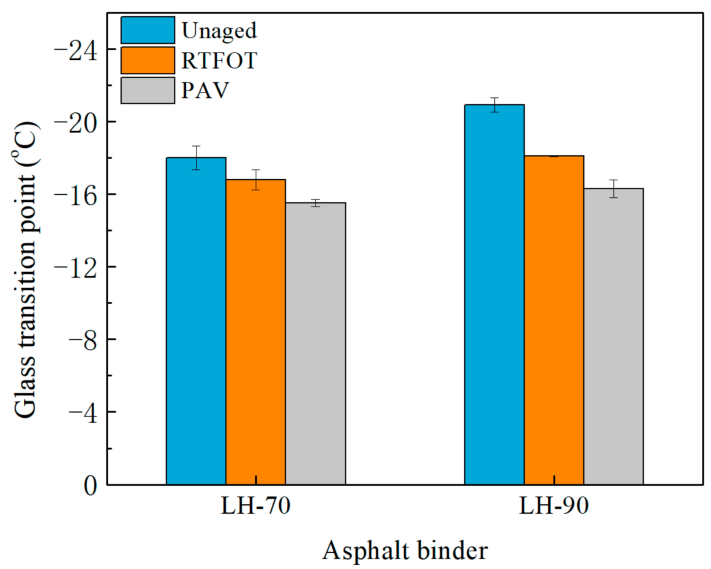

(a)

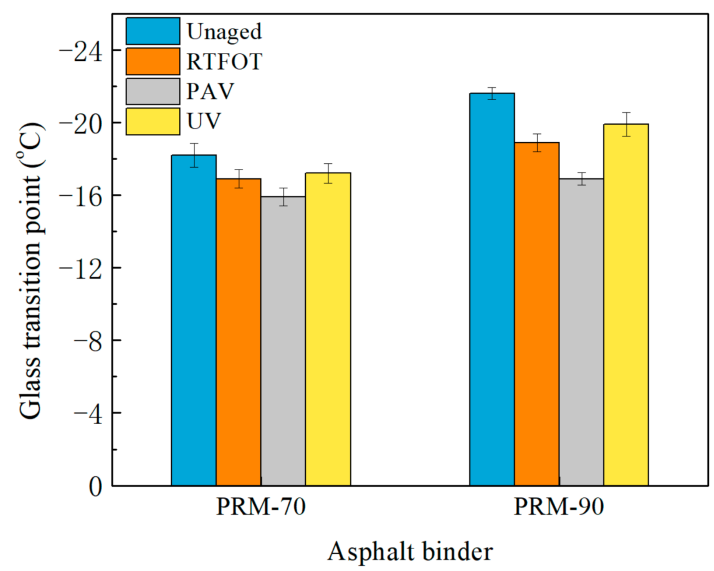

(b)

Figure 5. The glass transition point of all the tested binders: (a) Base bitumen, (b) PRM-modified bitumen. 


\subsection{Physical Properties Analysis}

\subsubsection{Viscosity Change Analysis by VAI}

The VAI values of PRM-modified bitumen, including the base bitumen, after the RTFOT, PAV, and UV aging, are plotted in the Figure 6. The higher VAI means that the bitumen samples are more sensitive to aging. As can be seen, the PRM-modified bitumen after PAV aging shows the highest VAI value, followed by RTFOT aging, and the VAI value after UV aging is the smallest. The difference in the VAI value may be due to the transition of SARA fractions brought about by the aging effect, which eventually led to the increase of viscosity for bitumen after aging. Moreover, the VAI values of PRM-90 after RTFOT and PAV are higher than those of PRM-70, whereas the VAI value of PRM-90 after UV is lower than that of PRM-70. It indicates that the influence of short- and long-term thermal-oxidation aging on PRM-90 is more significant than PRM-70 when evaluated using the VAI value. In terms of UV aging, the deterioration of PRM-70 is faster than that of PRM-90 after PAV aging.

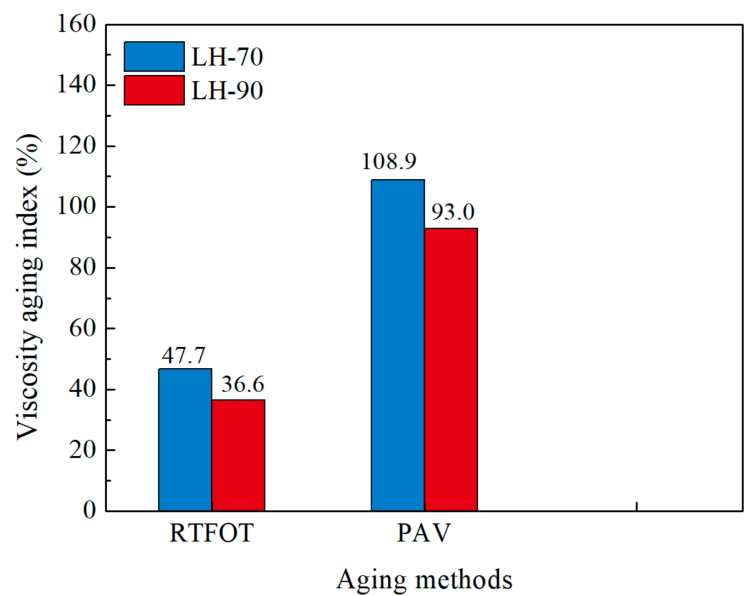

(a)

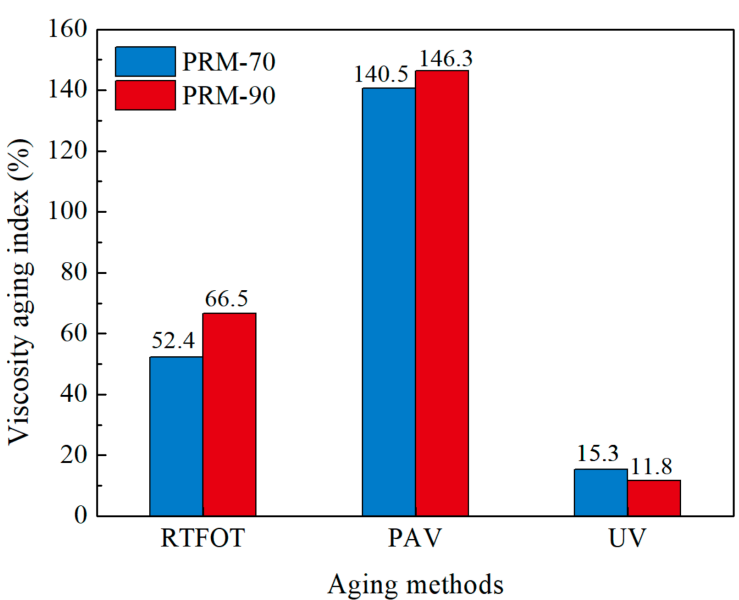

(b)

Figure 6. Viscosity aging index of the base bitumen (a) and PRM-modified bitumen (b) after RTFOT, PAV, and UV aging.

\subsubsection{Penetration Change Analysis by $R P R$}

Figure 7 shows the retained penetration ratio (RPR) of RTFOT, PAV, and UV-aged PRM-modified bitumen samples, including the base bitumen samples. The RPR of PRMmodified bitumen was reduced after thermal-oxidation aging and UV aging. A lower $R P R$ value implies a more serious aging impact. Similar to the result of VAI, the degree of decrease after PAV is the largest and the decreasing degree after UV radiation is least. PRM-70 bitumen presented a better performance in thermal-oxidation resistance than PRM-90. However, compared with UV aging resistance evaluated by VAI, the deterioration rate of physical properties for PRM-70 is much smaller than that of PRM-90. 


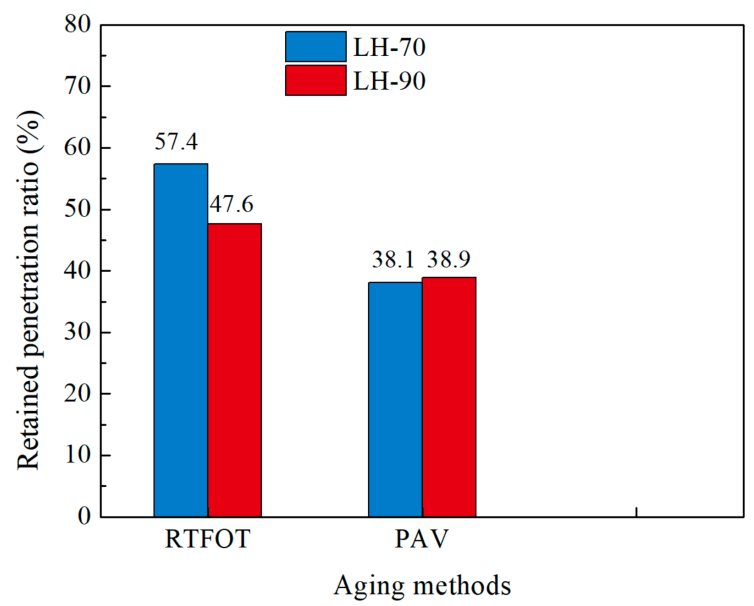

(a)

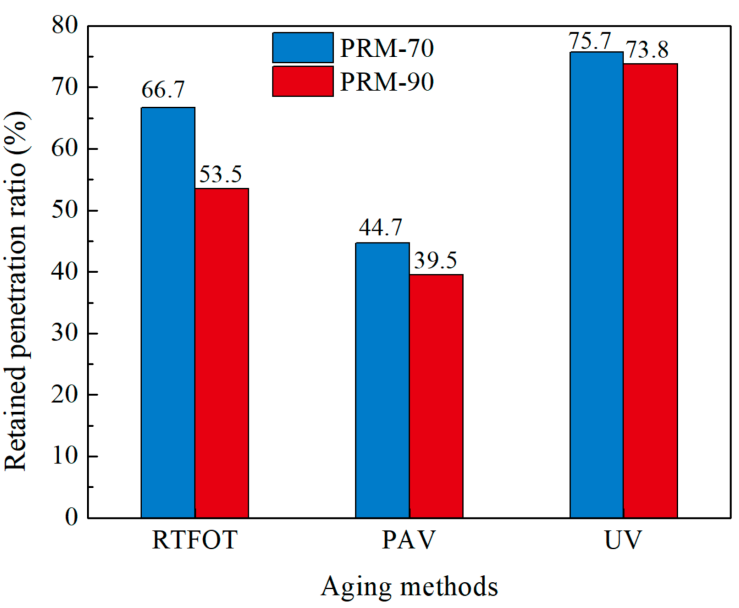

(b)

Figure 7. Retained penetration aging index of the base bitumen (a) and PRM-modified bitumen (b) after RTFOT, PAV, and UV aging.

\subsubsection{Softening Point Change Analysis by SPI}

Figure 8 describes the variance in softening point increment (SPI) of two PRMmodified bitumen before and after aging, including the base bitumen. Generally, a large increment of the softening point means a gap between original and aged bitumen. Obviously, it can be seen that the physical property of the softening point of the binders has been significantly improved after the PAV test. The increased trends of SPI for the two PRM-modified bitumen are very similar to their VAI, and the magnitude order of SPI is consistent among different aging methods, which is consistent with the changing trend of VAI.

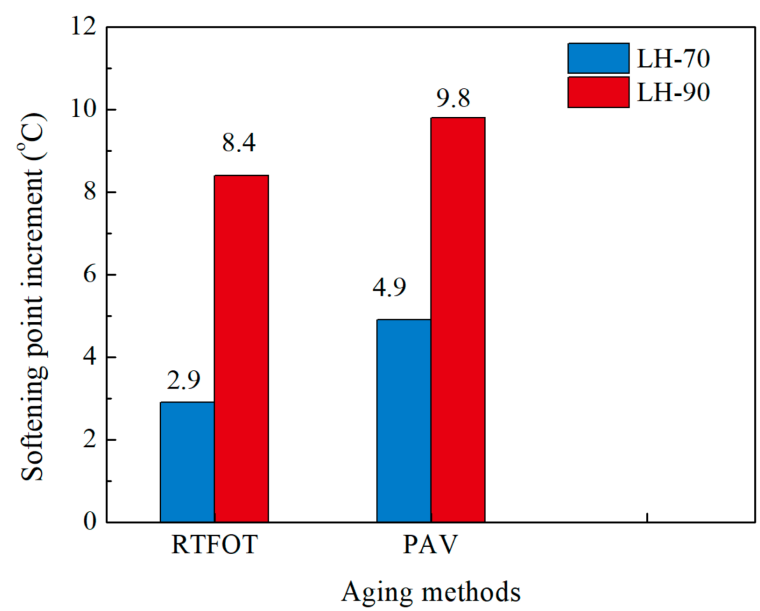

(a)

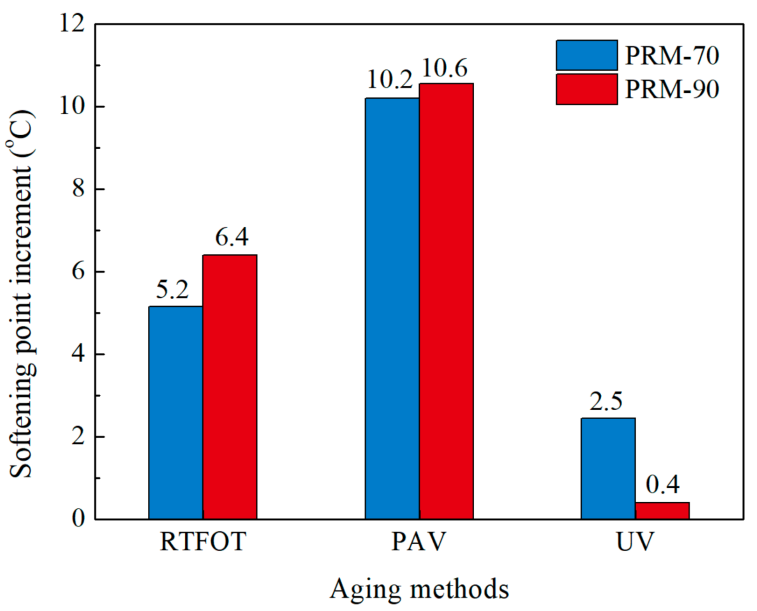

(b)

Figure 8. Softening point increment of the base bitumen (a) and PRM-modified bitumen (b) after RTFOT, PAV, and UV aging. 
By using the indexes of VAI, RPR, and SPI, the analyses of the influence of RTFOT, $\mathrm{PAV}$, and UV aging on bitumen performance imply that the deterioration degree of the physical properties of PRM-90 is larger than that of PRM-70 during thermal-oxidation aging. However, when using the semi-empirical aging index to evaluate the UV aging resistance of PRM-90 and PRM-70, there is no consistency in the results presented. It can be concluded that the same PRM-modified bitumen has different sensitivities to thermaloxidation aging and UV aging. There is a big difference between the thermal-oxidation aging resistance and UV aging resistance. The thermal-oxidation aging evaluation results obtained by semi-empirical aging index cannot accurately reflect its UV aging resistance.

\subsection{Rheological Analysis}

\subsubsection{Temperature Sweeps}

The Isochronal plots of PRM-modified bitumen, including the base bitumen, before and after aging are plotted in Figure 9. Compared to the unaged PRM-modified bitumen, it was observed that PRM-70 and PRM-90 have larger $G^{*}$ values after aging. For PRM-modified bitumen aged by PAV, $G^{*}$ is higher than the samples aged by RTFOT and UV, which implies the highest age hardening degree was caused by the oxidation and volatilization of light compounds of bitumen [28]. With respect to the phase angle, the variation of $\delta$ shows more complex behaviors. For the aged bitumen, it is observed that the $\delta$ of UV-aged bitumen is the highest and the $\delta$ of PAV-aged bitumen is the lowest, which implies a remarkable transformation of the viscous component to an elastic component in bitumen. When compared with unaged bitumen, it can be seen that $\delta$ of PRM-modified bitumen is higher than that of the sample after aging at low and medium temperatures. This can be explained by the fact that the aging process promotes the increases of the elastic component of bitumen, which directly leads to the reduction of $\delta$. However, when the temperature reaches $72{ }^{\circ} \mathrm{C}$, the $\delta$ values of aged PRM-modified bitumen begin to be higher than that of unaged PRM-modified bitumen. Moreover, this result is more prominent for PRM-90 bitumen. It is widely recognized that the phase angle can be used as a sensitive indicator of the damage of the polymeric network structure in bitumen [29-31]. In this sense, the higher $\delta$ values displayed at higher temperatures may imply the broken of polymeric network and deterioration of the PRM modifier in bitumen.

By using the complex modulus index $\left(G^{*}\right.$ index, $\left.C M I\right)$ and phase angle index $\left(G^{*}\right.$ index, $P A I)$, the aging effect on PRM-modified bitumen was evaluated by Equations (8) and (9).

$$
\begin{aligned}
G * \text { index } & =\frac{G * \text { aged }}{G * \text { unaged }} \\
\delta \text { index } & =\frac{\delta_{\text {aged }}}{\delta_{\text {unaged }}}
\end{aligned}
$$

The $G^{*}$ index and $\delta$ index of PRM-modified bitumen, including the base bitumen, before and after aging are plotted in Figure 10. A higher $G^{*}$ index and a lower $\delta$ index imply greater deterioration of the rheological performance for bitumen. As can be seen, with the increase of temperature, the overall curves of the $G^{*}$ index first increase and then decrease with a turning point at medium temperature. However, the temperature point corresponding to the turning point of $G^{*}$ value is inconsistent. The $\delta$ index shows a continuous increasing trend with the increase of temperature. Compared with PRM-70, PRM-90 shows a larger $G^{*}$ index within the temperature scope and a smaller $\delta$ index at high temperatures. In this sense, it can be concluded that the influence of thermal-oxidation and UV aging on the high-temperature rheological performance of PRM-90 is more obvious than that of PRM-70. 


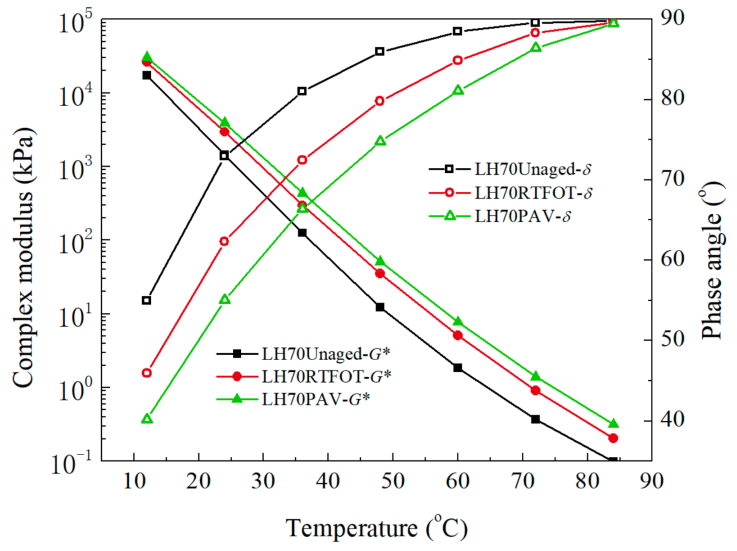

(a)

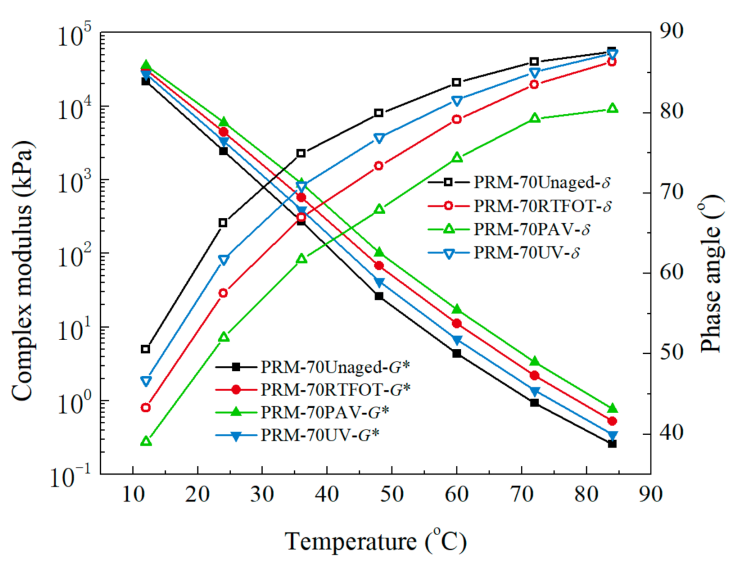

(c)

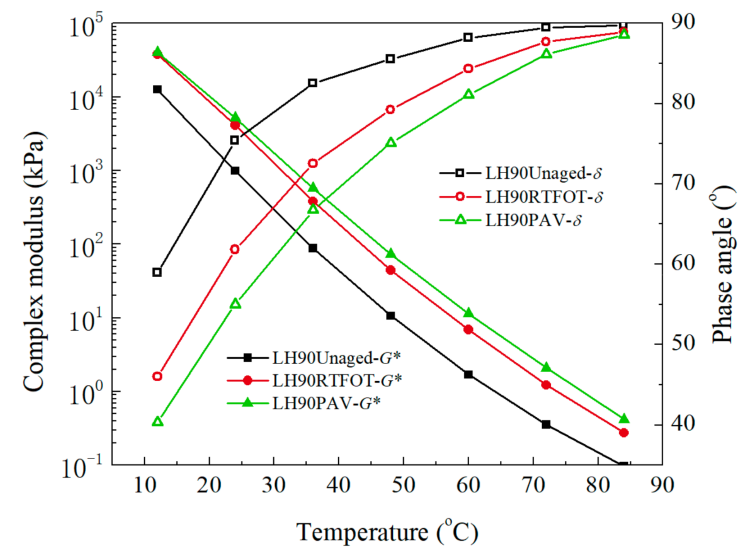

(b)

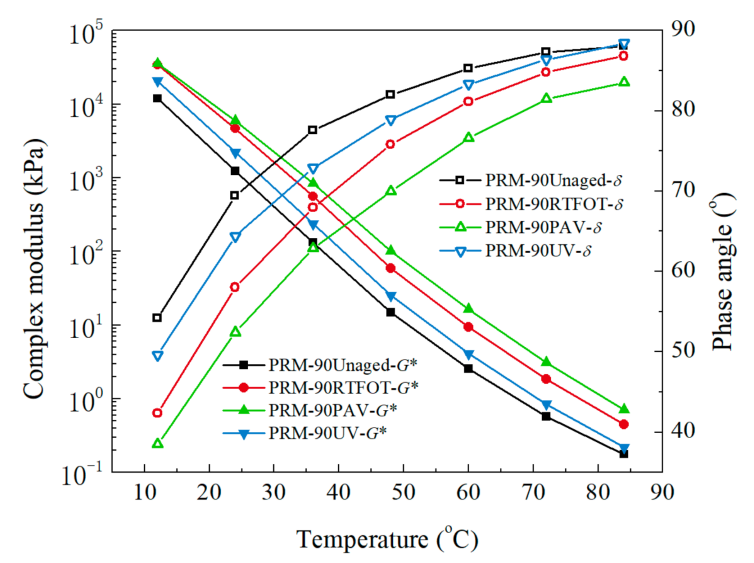

(d)

Figure 9. Effects of aging on the temperature dependence of rheological properties of bitumen: (a) LH-70 base bitumen, (b) PRM-70-modified bitumen, (c) LH-90 base bitumen, (d) PRM-90-modified bitumen.

\subsubsection{Master Curves}

Based on the "Time-Temperature Superposition" principle (TTSP), the master curves of $G^{*}$ and $\delta$ versus the reduced frequency are constructed at a reference temperature of $36^{\circ} \mathrm{C}$. By using the master curves, the rheological behaviors of bitumen can be presented over a wide range of reduced frequencies. The master curves of $G^{*}$ and $\delta$ for the unaged and aged PRM-70- and PRM-90-modified bitumen, including the base bitumen, are plotted in Figures 11 and 12, respectively. As expected, there is a significant increase in $G^{*}$ throughout the frequency range for PRM-70- and PRM-90-modified bitumen after thermo-oxidative and UV aging, especially in the low and intermediate loading frequencies, which indicates stiffening of bitumen due to aging. Aged PRM-modified bitumen exhibits lower $\delta$ values than the respective unaged sample at intermediate and high loading frequencies whereas the $\delta$ of bitumen after aging has higher values at high temperatures. This result is in accordance with the previous research of Zeng and Dondi et al. [29,32], which may be attributed to the increase of the elastic component and the deterioration of the internal networks in PRM-modified bitumen. 


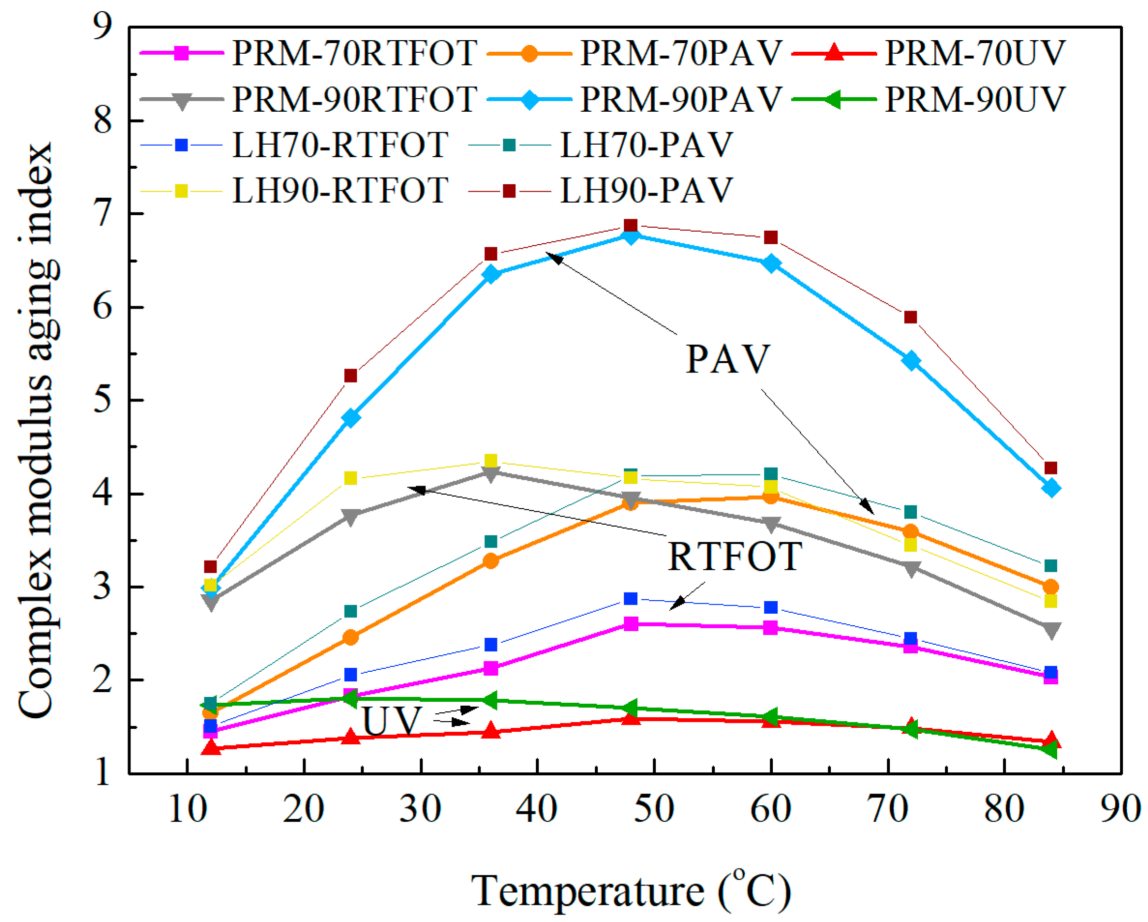

(a)

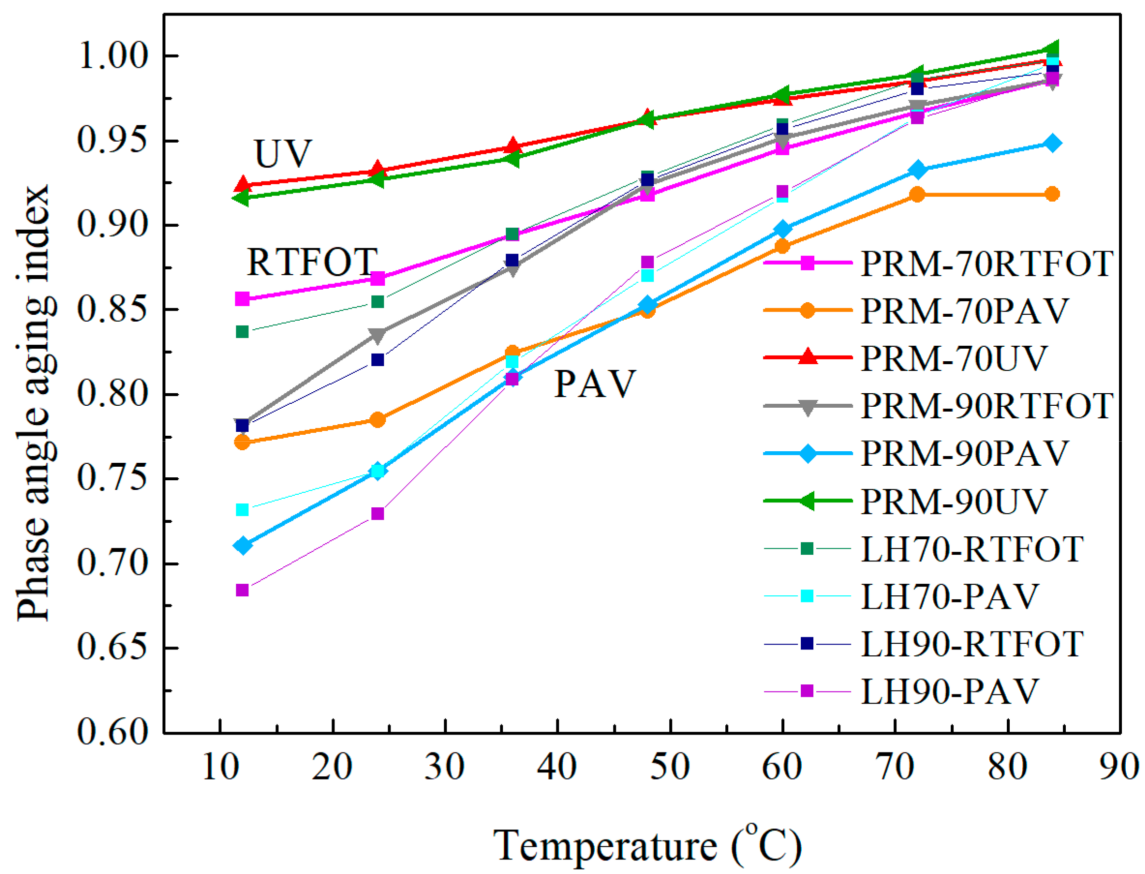

(b)

Figure 10. Effects of aging on the temperature dependence of rheological properties of bitumen: (a) Complex modulus, (b) phase angle aging index. 


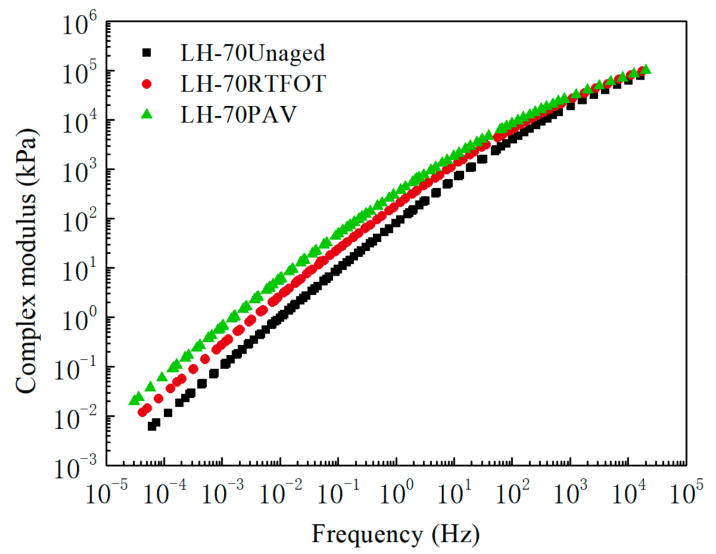

(a)

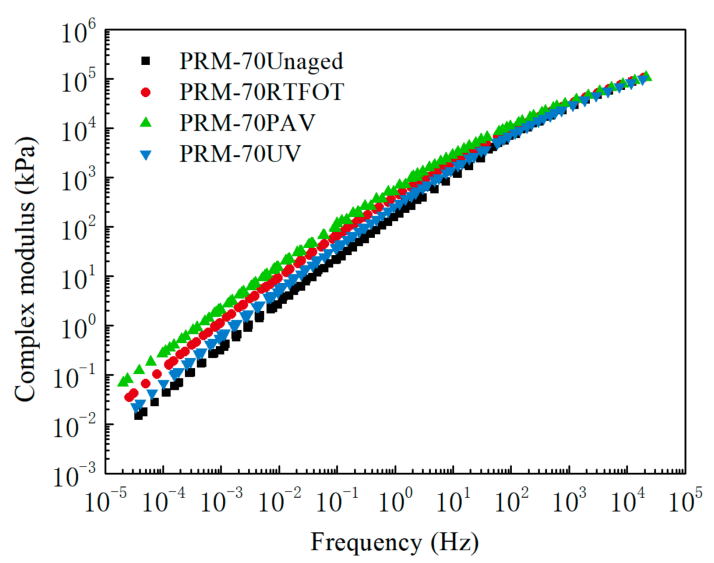

(c)

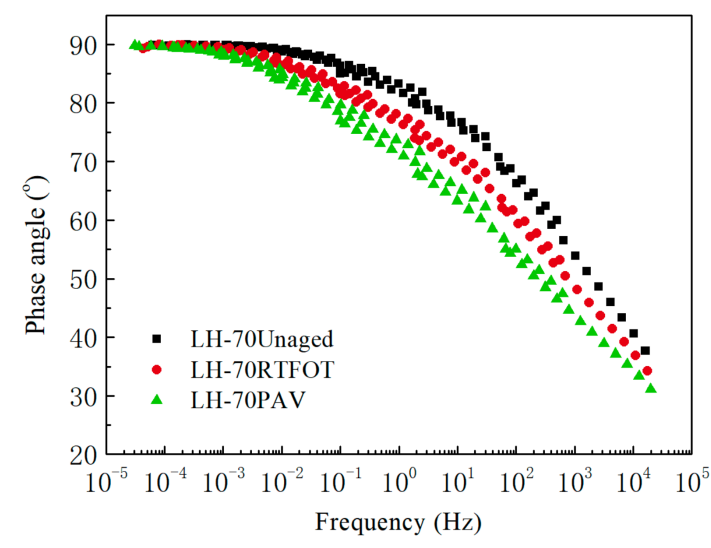

(b)

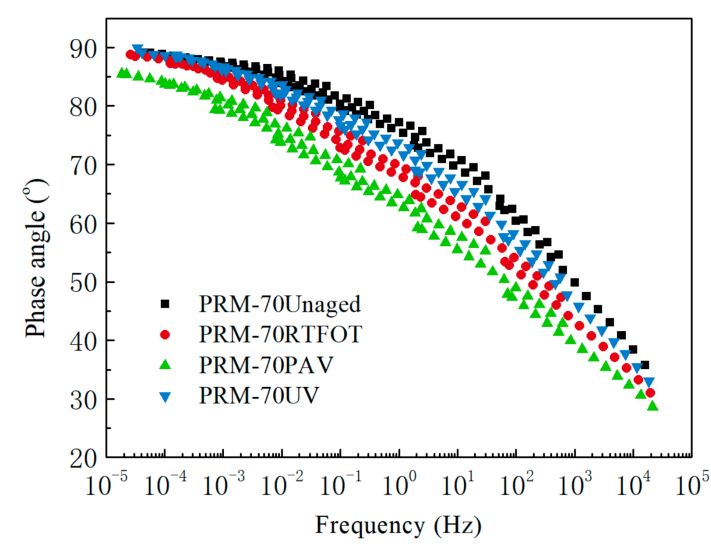

(d)

Figure 11. Effects of aging on the master curves of complex modulus $\left(G^{*}\right)$ and phase angle $(\delta)$ : (a) $G^{*}$ for LH-70, (b) $\delta$ for LH-70, (c) G* for PRM-70, (d) $\delta$ for PRM-70.

The Christensen-Anderson-Marasteanu (CAM) model [33,34] is used to characterize the master curves of the $G^{*}$ and $\delta$, as follows:

$$
\begin{gathered}
G^{*}=\frac{G_{\mathrm{g}}}{\left[1+\left(f_{\mathrm{c}} / \alpha_{T} f\right)^{k}\right]_{\mathrm{e}}^{m_{\mathrm{e}} / k}} \\
\delta=\frac{90 m_{\mathrm{e}}}{1+\left(f_{\mathrm{c}} / f\right)^{k}}
\end{gathered}
$$

where $f$ is the loading frequency, $f_{\mathrm{c}}$ is a location parameter, $G_{\mathrm{g}}$ is the glassy shear modulus, $k$ and me is a dimensionless shape parameter, and $\alpha_{T}$ is shift factor related to the WilliamsLandel-Ferry (WLF) equation:

$$
\log \left(\alpha_{T}\right)=\frac{-C_{1}\left(T-T_{\text {ref }}\right)}{C_{2}+\left(T-T_{\text {ref }}\right)}
$$

where $\alpha_{T}$ is the shift factor at temperature $T$, and $C_{1}$ and $C_{2}$ are the empirical constants. For example, Figure 13 illustrates the $G^{*}$ master curves of PRM-90-modified bitumen pre- and post-PAV aging. According to the method developed by Cavalli et al. [35], the rheologic aging index $(R A I)$ is determined by calculating the difference between the area under the aged and virgin $G^{*}$ master curves. 


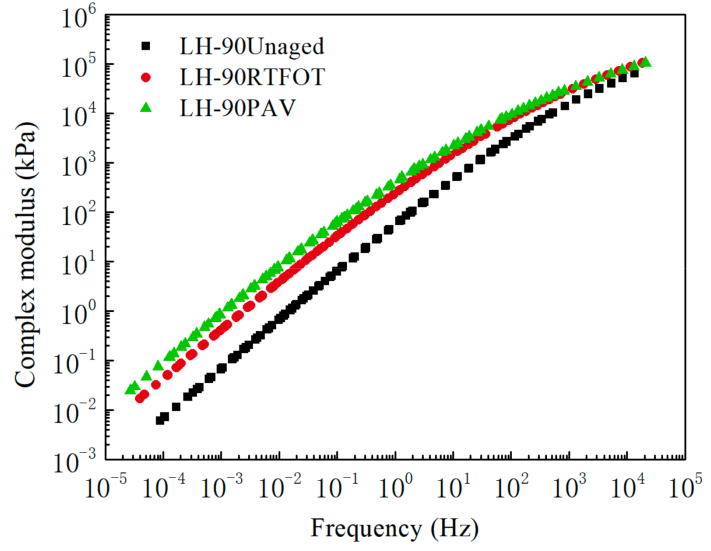

(a)

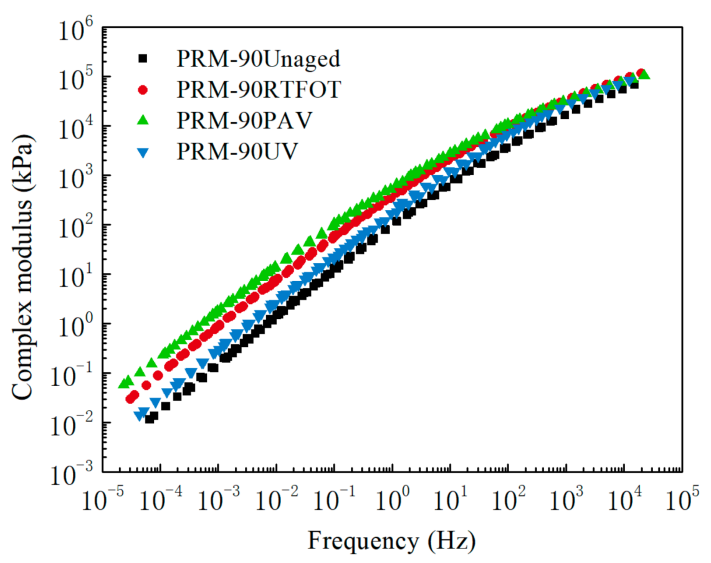

(c)

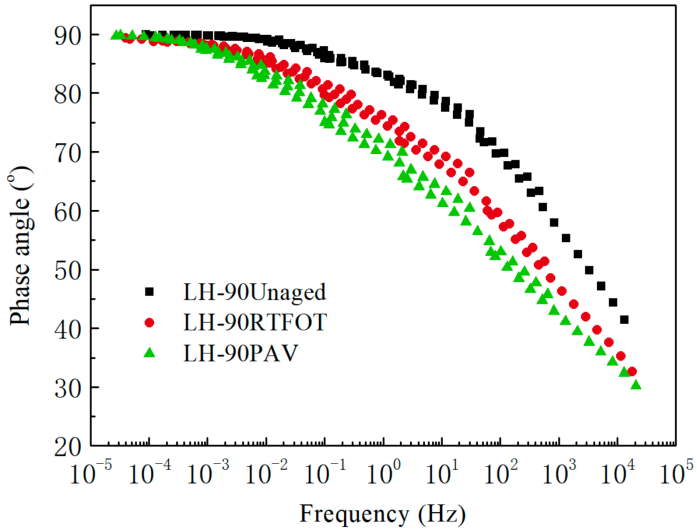

(b)

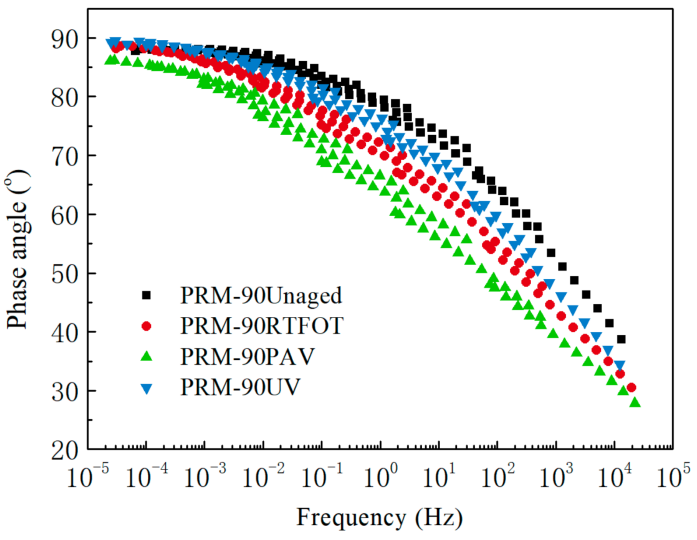

(d)

Figure 12. Effects of aging on the master curves of $G^{*}$ and $\delta$ : (a) $G^{*}$ for LH-90, (b) $G^{*}$ for PRM-90, (c) $\delta$ for LH-90, (d) $\delta$ for PRM-90.

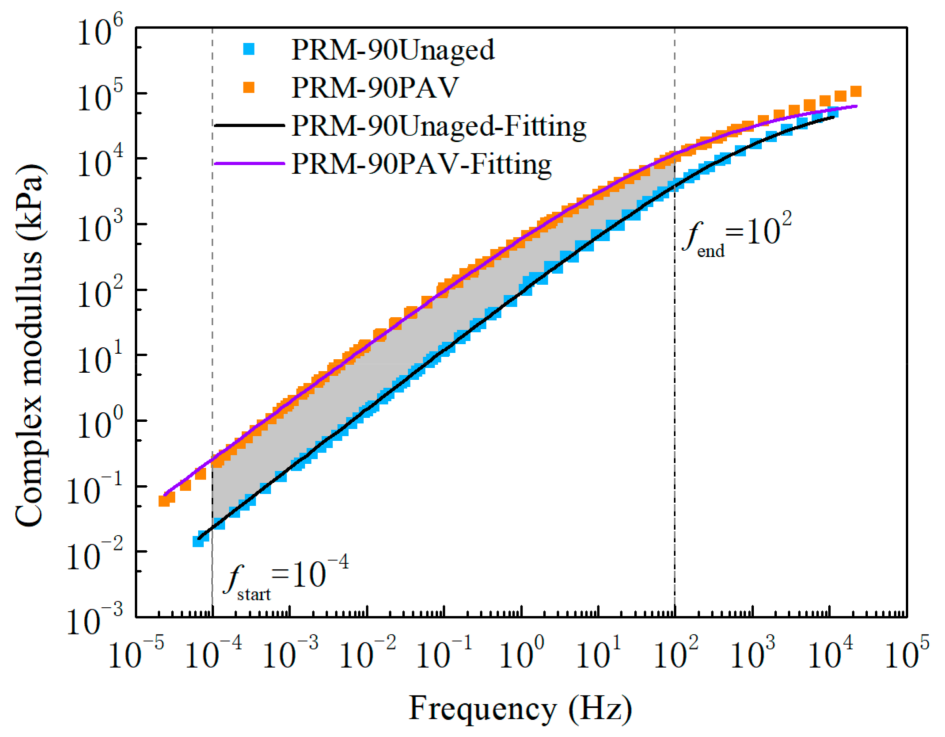

Figure 13. The illustration of the calculation of the aging index using the area between the aged and unaged $G^{*}$ master curve. 
In this research, the unified reduced frequency limits from $10^{-4}$ to $10^{2}$ was selected for the evaluations of all the aging effects, according to Equation (13):

$$
R A I=\int_{-4}^{2} \log |G *|\left(\tilde{\xi}_{\text {aged }}^{\sim}\right)-\log |G *|\left(\dot{\xi}_{\text {unaged }}^{\sim}\right) d \xi
$$

where $\left|G^{*}\right|$ is the complex modulus and $\xi$ is the logarithm of the reduced frequency between the integral limits. According to Equation (6), the integration was carried out and the area between the aged and unaged $G^{*}$ master curves in the log-log scale was subsequently obtained, as listed in Table 2.

Table 2. Rheological aging index (RAI) for the base and PRM modified bitumen.

\begin{tabular}{cccc}
\hline Sample & $\begin{array}{c}\text { Area Under the } \\
\text { Master Curve } \\
{[\mathbf{l g}(\mathbf{P a}) \cdot \mathbf{l g}(\mathbf{H z})]}\end{array}$ & $\begin{array}{c}\text { Area between Virgin } \\
\text { and Aged Binder } \\
{[\mathbf{l g}(\mathbf{P a}) \cdot \mathbf{l g}(\mathbf{H z})]}\end{array}$ & $\begin{array}{c}\text { Percentage of Virgin } \\
\text { Area (\%) }\end{array}$ \\
\hline PRM-70Unaged & 25.93 & - & - \\
PRM-70RTFOT & 28.37 & 2.44 & 9.41 \\
PRM-70PAV & 29.59 & 3.66 & 14.11 \\
PRM-70UV & 27.09 & 1.16 & 4.47 \\
LH-70-Unaged & 23.47 & - & - \\
LH-70-RTFOT & 25.75 & 2.28 & 9.71 \\
LH-70-PAV & 27.47 & 4 & 17.04 \\
PRM-90Unaged & 24.16 & - & - \\
PRM-90RTFOT & 27.98 & 3.82 & 15.81 \\
PRM-90PAV & 29.32 & 5.16 & 21.36 \\
PRM-90UV & 25.78 & 1.62 & 6.71 \\
LH-90-Unaged & 22.56 & - & - \\
LH-90-RTFOT & 26.57 & 4.01 & 24.77 \\
LH-90-PAV & 28.12 & 5.56 & \\
\hline
\end{tabular}

As presented in Table 2, the influence of different aging methods on the virgin PRMmodified bitumen shows a significant difference. The RAIs of aged PRM-90-modified bitumen are all higher than that of PRM-70 after the same aging method. Meanwhile, the PAV-aged PRM-90 bitumen presents higher RAI values, which indicates that the most significant change of rheological properties, particularly $G^{*}$, occurred after PAV aging.

\subsubsection{Permanent Deformation Resistance by MSCR}

Aiming at assessing the effect of aging on the linear and non-linear behaviors of bitumen, the MSCR test was carried out on the aged and virgin PRM-modified bitumen. The MSCR test results with the corresponding percentage recovery $(R \%)$ and non-recoverable compliance (Jnr) of bitumen are presented in Figures 14 and 15. 


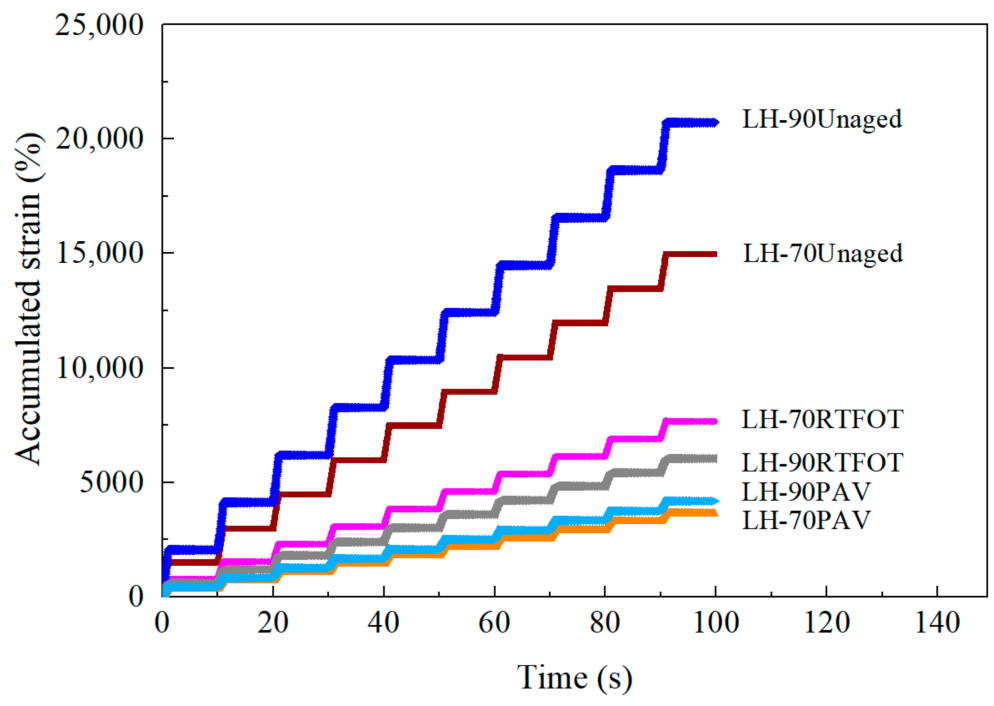

(a)

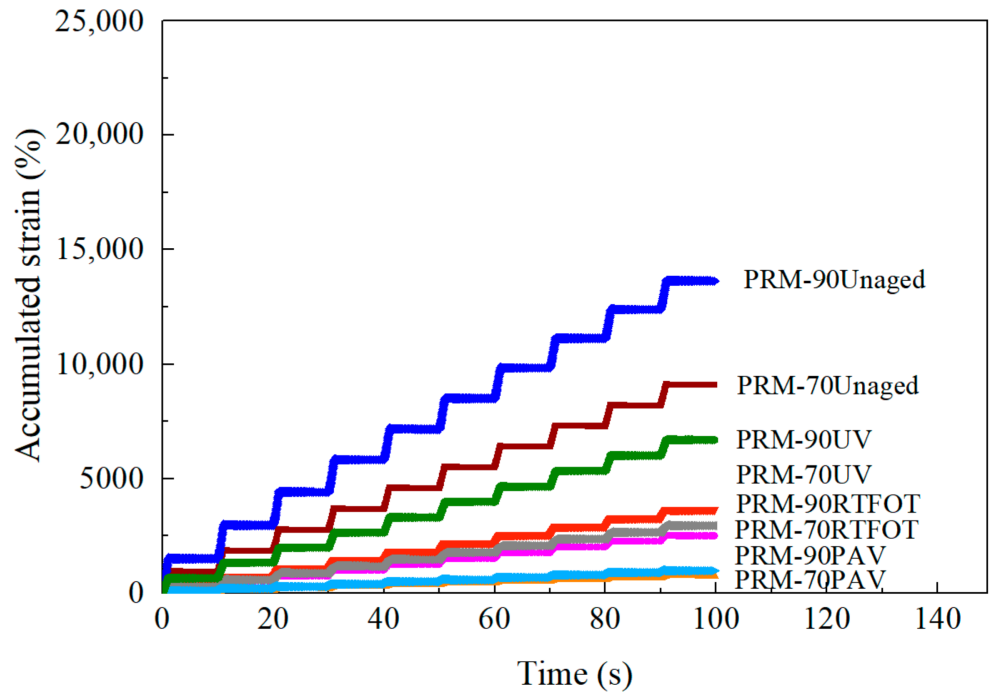

(b)

Figure 14. MSCR results of the base bitumen (a) and PRM-modified bitumen (b) samples under a stress level of $3.2 \mathrm{kPa}$ at $60^{\circ} \mathrm{C}$.

As can be seen, the strains of the aged and unaged PRM-modified bitumen increase and accumulate rapidly under the circle loading $3.2 \mathrm{kPa}$. The accumulated strains of PRM-90 are larger than that of PRM-70, which implies that PRM-90 is more susceptible to the external loads. After the aging process, the aged bitumen presents a smaller growth rate of strain, which means that the creep property and the elastic component of PRM-modified bitumen are reduced. 


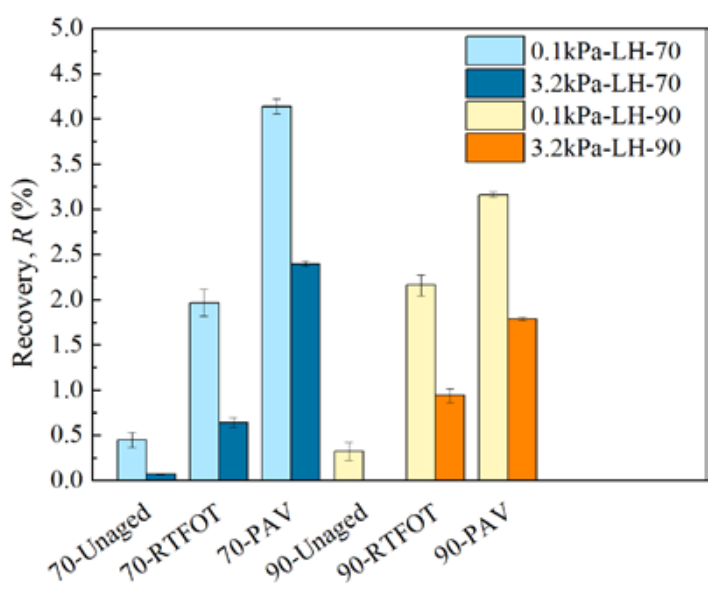

(a)

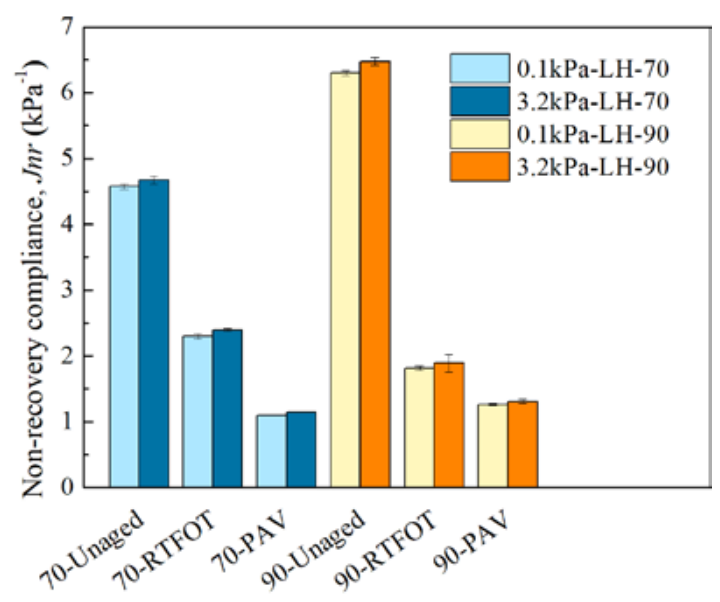

(c)

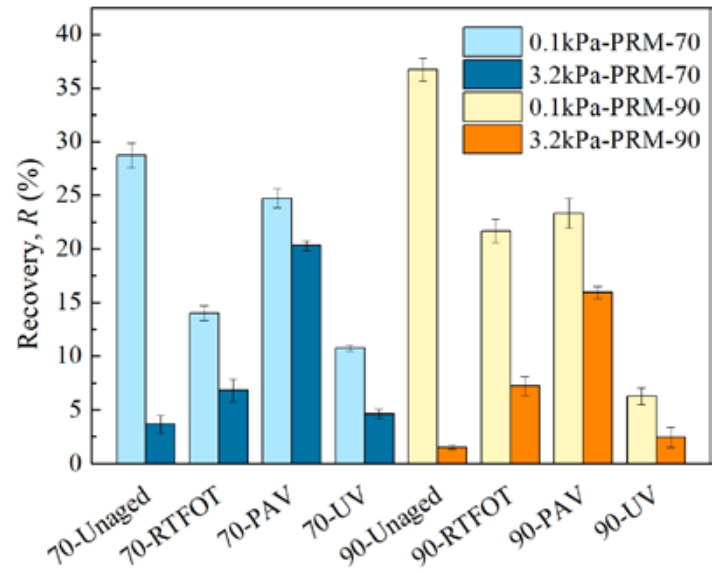

(b)

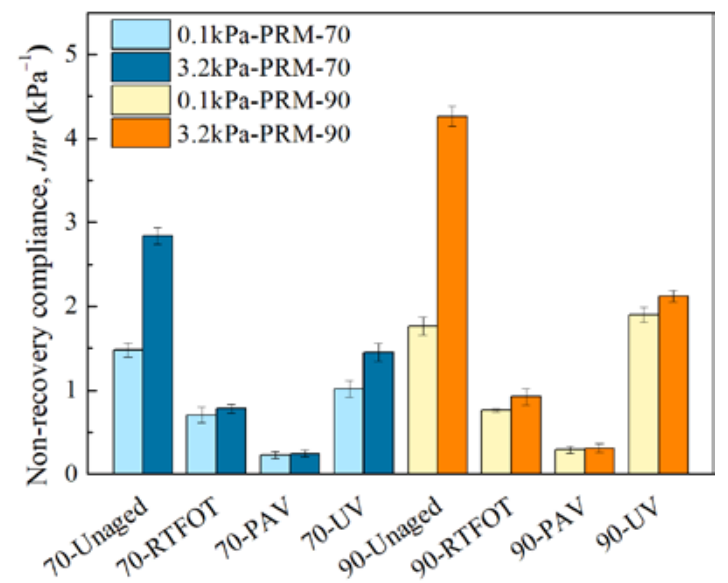

(d)

Figure 15. The recovery (\%) and $J n r\left(\mathrm{kPa}^{-1}\right)$ of the base bitumen and PRM-modified bitumen samples: (a) Recovery of base bitumen, (b) recovery of PRM-modified bitumen, (c) Jnr of the base bitumen; (d) Jnr of PRM-modified bitumen.

Figure 15 presents the MSCR results of $R \%$ and $J n r$ for the bitumen, and as expected, the $R \%$ and $J n r$ measured at the stress level of $3.2 \mathrm{kPa}$ are lower and higher, respectively, than those measured at the stress level of $0.1 \mathrm{kPa}$. It was found that the aged, modified bitumen have lower $J n r$ as compared to the virgin bitumen at both creep loading levels, which indicates the increase of the stiffness of bitumen due to the impact of the aging process. In terms of the effect of aging on the $R \%$, it could be noted that the unaged PRM-70and PRM-90-modified bitumen exhibit the largest values of $R \%$ compared to their aged samples at the creep loading level of $0.1 \mathrm{kPa}$, while the aged bitumen have higher $R \%$ as compared to the virgin bitumen at the higher level of $3.2 \mathrm{kPa}$. Meanwhile, the increase of aging levels will lead to the increase in elasticity for the PRM-modified bitumen. This result directly shows that the elasticity of PRM-modified bitumen is susceptible to the creep loading level, and hence the $R \%$ is restricted by the dual factors of the creep loading level and the aging state.

\subsubsection{Low-Temperature Cracking Resistance by the Bending Beam Rheometer (BBR)}

The SENB test was conducted to evaluate the low-temperature performance of bitumen. Figure 16 illustrates a representative load-deflection curve from the SENB test. 


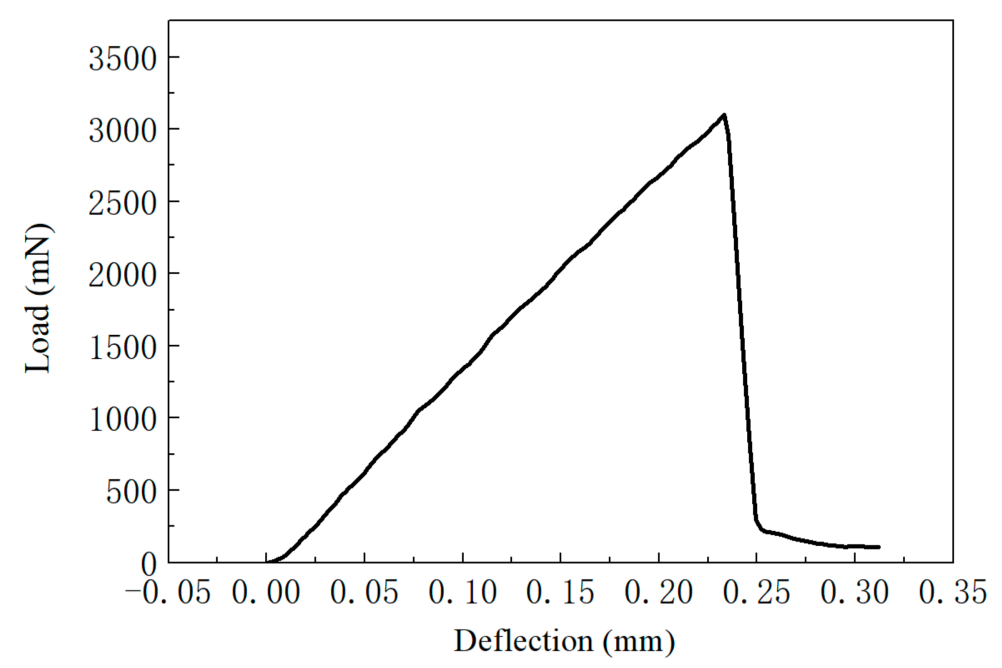

Figure 16. A representative load-deflection curves of bitumen obtained from the SENB test at $-12{ }^{\circ} \mathrm{C}$.

By using the load-deflection curves from the SENB test, the fracture energy for all of the tested binders at $-12{ }^{\circ} \mathrm{C}$ was calculated for the evaluation of low-temperature performance, as illustrated in Figure 17. It was observed that the aging process may result in a lower fracture energy. The PAV-aged samples exhibited the smallest fracture energy value. Compared to unaged samples, the fracture energy value of PRM-70 and PRM-90 after PAV aging decreased by $52.4 \%$ and $58.3 \%$, respectively. Compared with PRM-70, PRM-90 shows a larger $G_{f}$ index. Likewise, the fracture energy index $\left(G_{f}\right.$ index, FEI) is proposed to quantitatively evaluate the effect of aging. The $G_{f}$ index is calculated as:

$$
G_{f} \text { index }=\frac{G_{f, \text { aged }}}{G_{f, \text { unaged }}}
$$

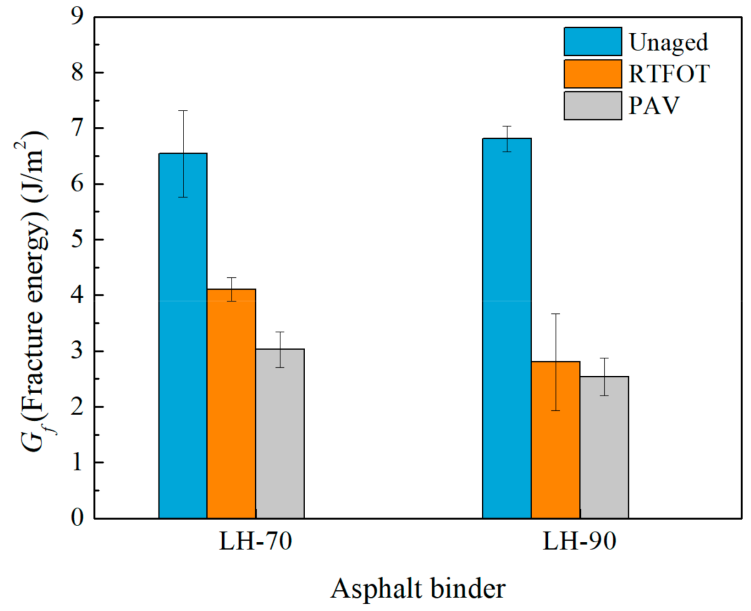

(a)

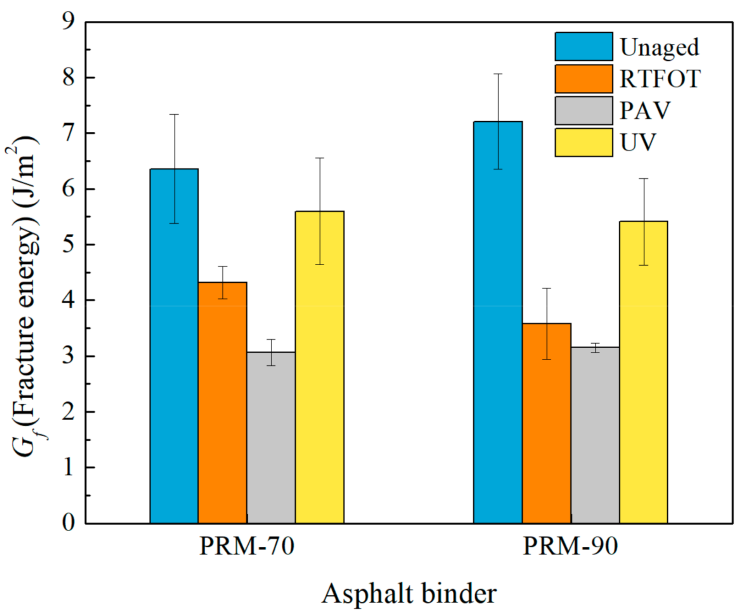

(b)

Figure 17. Fracture energy of all the tested binders at $-12{ }^{\circ} \mathrm{C}$ : (a) Base bitumen, (b) PRM-modified bitumen.

For PRM-70 bitumen, the $G_{f}$ index of the RTFOT-aged binder, the PAV-aged binder, and the UV-aged binder are $0.68,0.48$, and 0.88 , respectively. For PRM-90 bitumen, $G_{f}$ of the RTFOT-aged binder, the PAV-aged binder, and the UV-aged binder are $0.50,0.44$, and 0.75 , respectively. The above result indicates that the aging may make the pavement 
more vulnerable to low-temperature cracking. The influence of the aging process on the low-temperature performance of PRM-90 is more significant than that of PRM-70, which shows the consistency as compared to the variation of rheological properties.

\subsubsection{Fatigue Resistance by LAS}

The failure criteria employed in the LAS test are employed as the 35\% reduction in $G^{*} \sin \delta$ for the bitumen. The number of cycles to failure (also referred to as the fatigue life, Nf) at $5 \%$ strain for all the binders are shown in Figure 18. Obviously, the aging process accelerates the fatigue damage of the binders. The $N_{f}$ of RTFOT-, PAV-, and UV-aged PRM-90 bitumen is higher than that of unaged PRM-70 bitumen, which indicates that the fatigue resistance of PRM-90 bitumen outperformed PRM-70 binders. By using the LAS result, the fatigue life index ( $N_{f}$ index, $\left.F L I\right)$ was employed to evaluate the aging resistance of bitumen from the aspect of fatigue properties. It is calculated by Equation (15). The higher the $F L I$ value, the better the anti-aging resistance of the sample is.

$$
N_{f} \text { index }=\frac{N_{f \text {, aged }}}{N_{f, \text { unaged }}}
$$

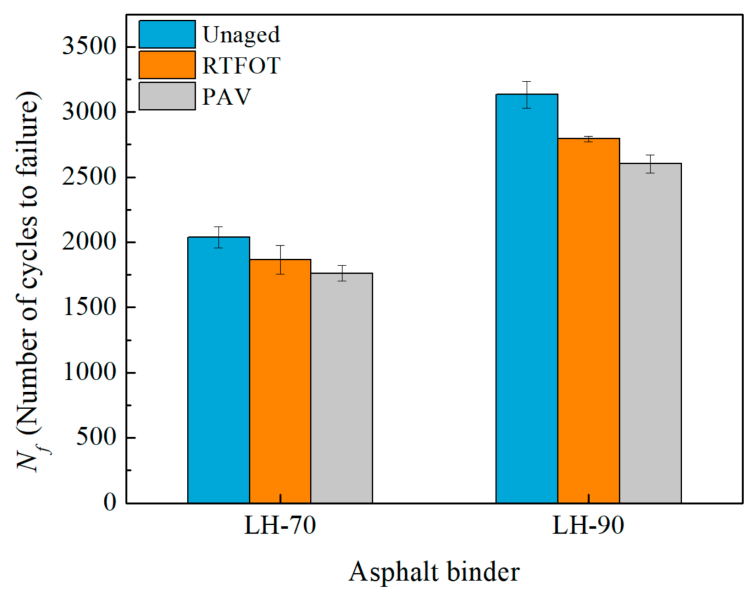

(a)

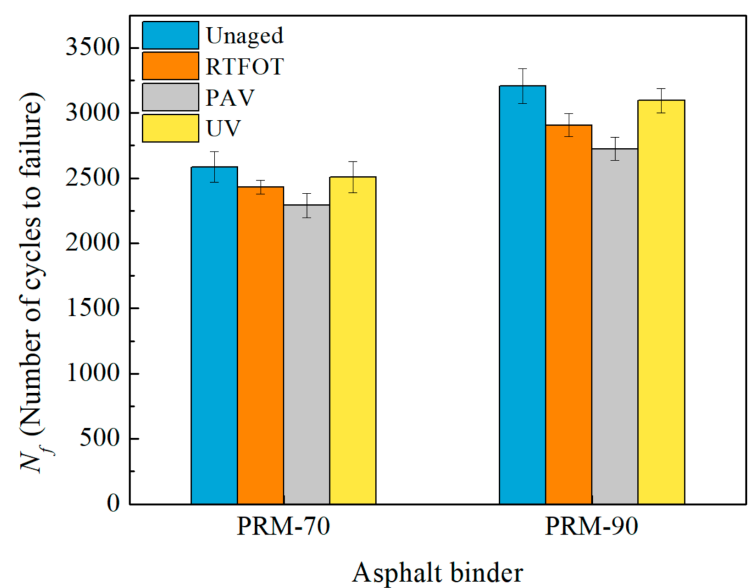

(b)

Figure 18. Number of cycles to failure of all the tested binders at 5.0\% strain and $10 \mathrm{~Hz}$ : (a) Base bitumen, (b) PRMmodified bitumen.

As can be seen in Figure 18a, for the base LH-70 bitumen, the $N_{f}$ index of the RTFOTaged binder and the PAV-aged binder are 0.92 and 0.86, respectively. For the base LH-90 bitumen, the $N_{f}$ index of the RTFOT-aged binder and the PAV-aged binder are 0.89 and 0.83, respectively. As shown in Figure 19b, for the PRM-70 bitumen, the $N_{f}$ index of the RTFOT-aged binder, the PAV-aged binder, and the UV-aged binder are 0.94, 0.89, and 0.97, respectively. For PRM- 90 bitumen, the $N_{f}$ index of the RTFOT-aged binder, the PAV-aged binder, and the UV-aged binder are $0.91,0.85$, and 0.97 , respectively. It can be concluded that different aging methods have little effect on the fatigue properties of PRM-modified bitumen samples. In addition, the above results also indicate that PRM-modified bitumen has potential advantages in resisting fatigue caused by aging. 


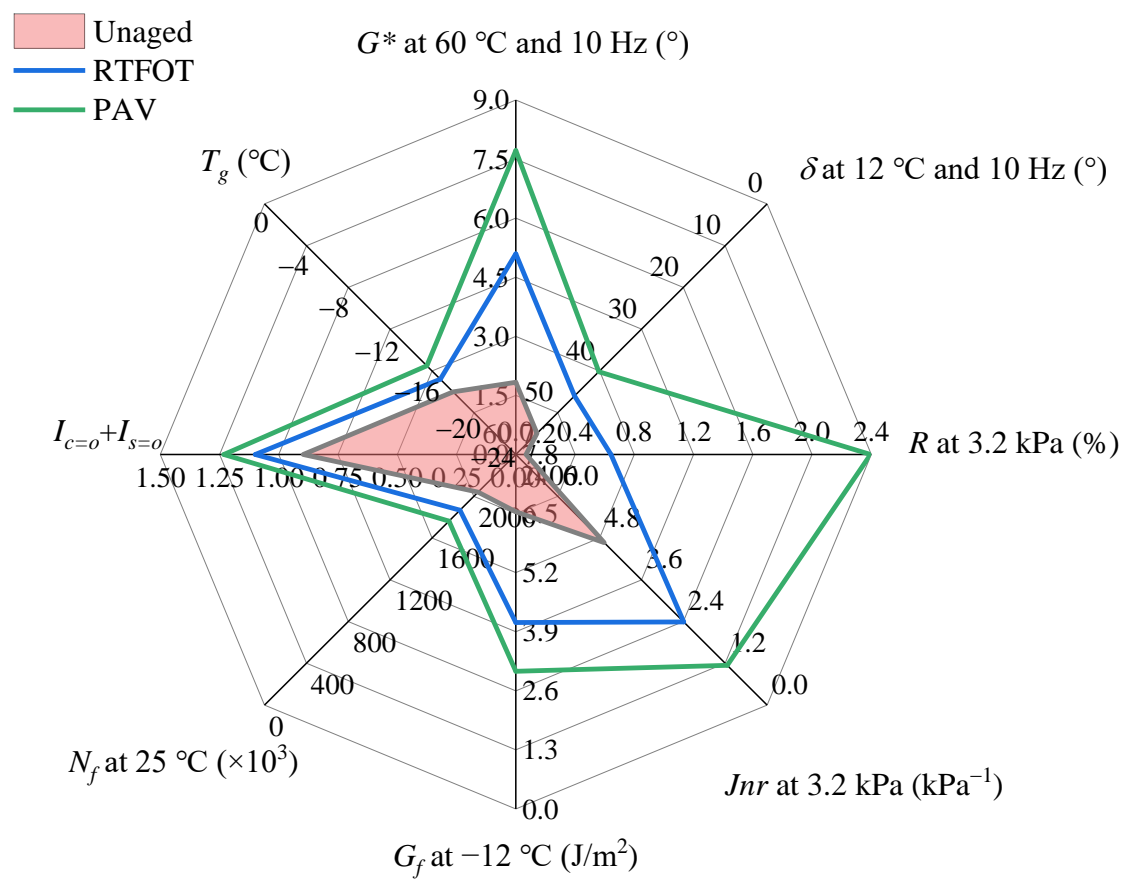

(a)

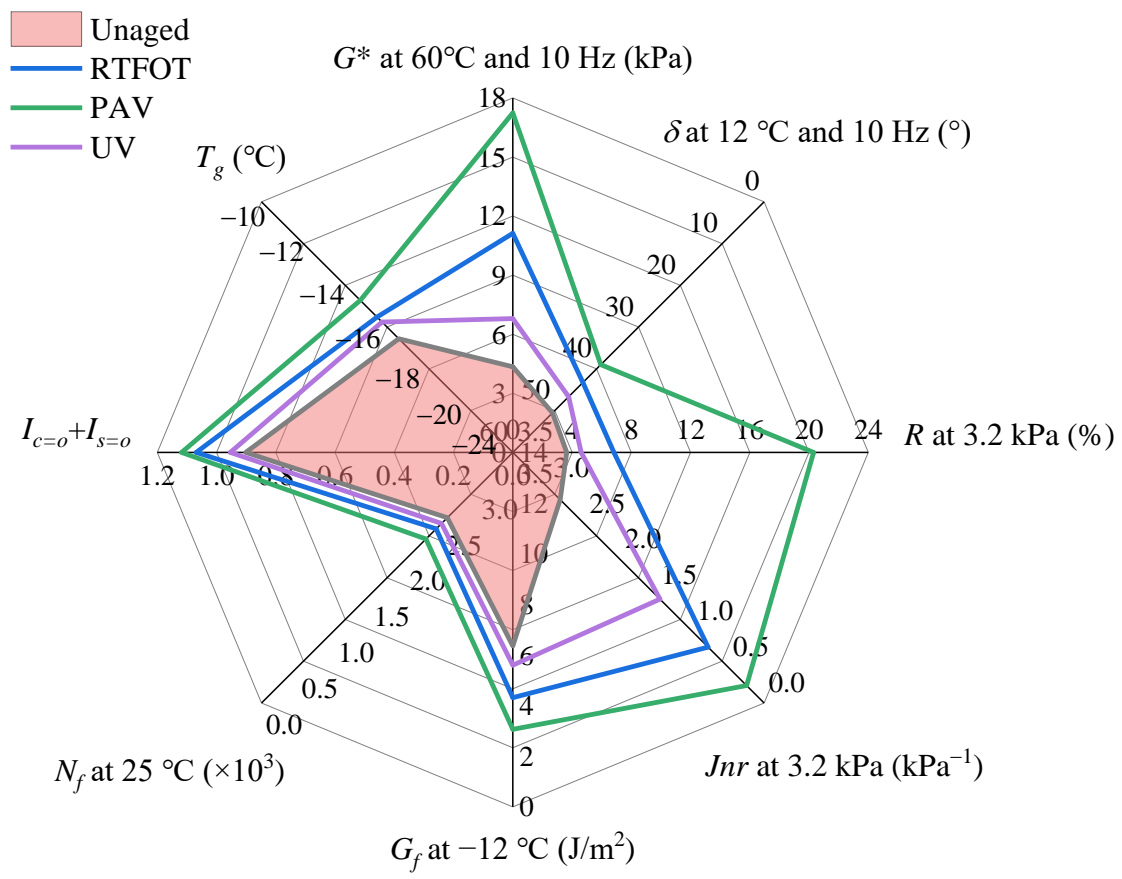

(b)

Figure 19. Cont. 


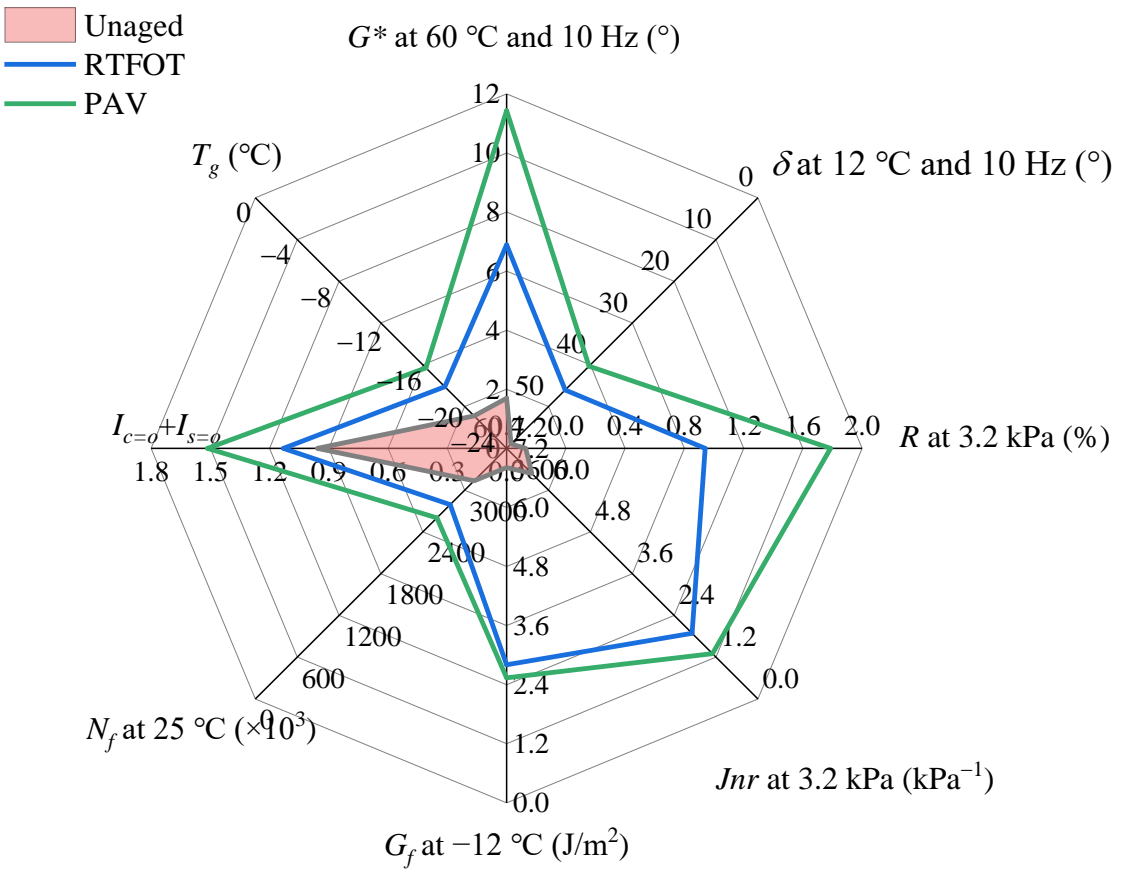

(c)

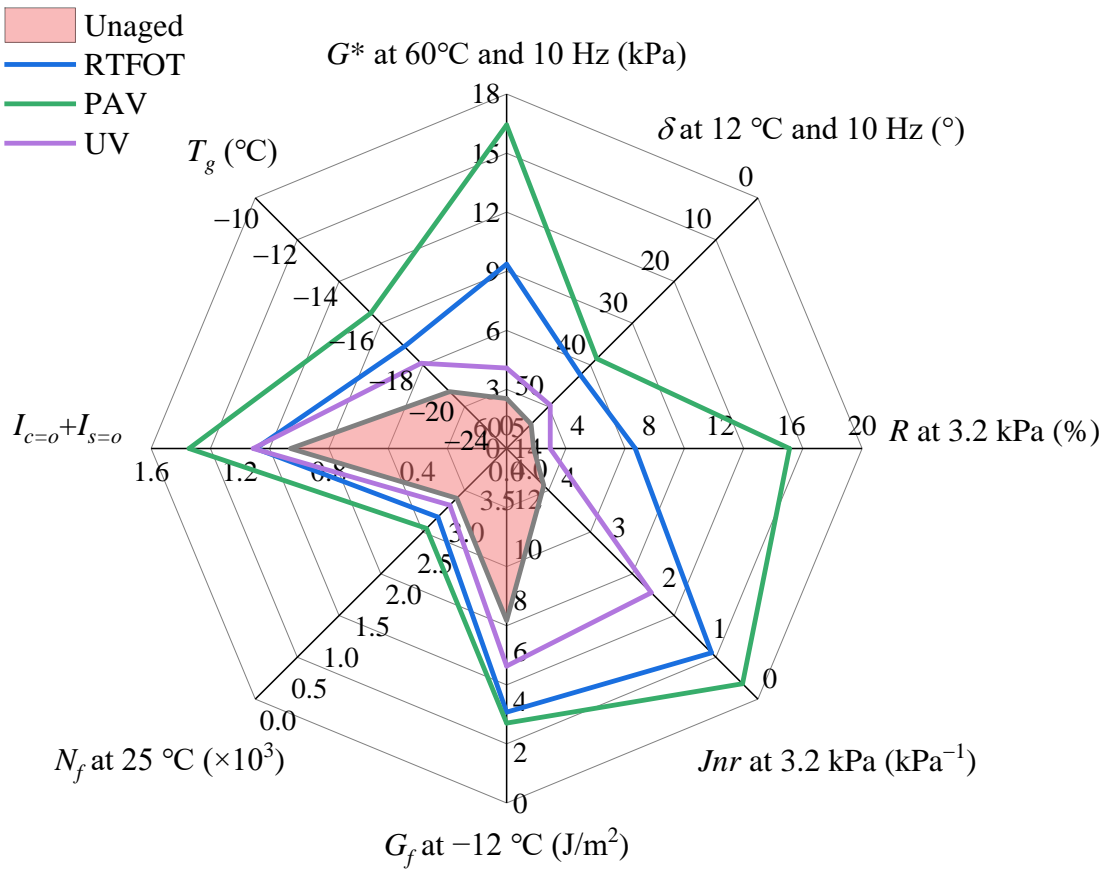

(d)

Figure 19. Radar charts of aging performance: (a) LH-70 base bitumen, (b) PRM-70-modified bitumen, (c) LH-90 base bitumen and (d) PRM-90-modified bitumen.

\subsection{Radar Charts}

By using the radar charts, the performance diagrams have been constructed for all the unaged and aged PRM-modified bitumen, as illustrated in Figure 19. The radar charts were plotted in such a way that the effect of aging on bitumen performance can be expected with an increasing distance from the axis cross or the radar origin. The aged bitumen that 
covered a larger area in the diagram implies that bitumen has better anti-aging resistance. Thus, the radar charts can be used for the assessment and comparison of bitumen based on their performance-relevant properties. As can be seen from Figure 19, it seems that the RTFOT, PAV, and UV aging result in a large degradation of high-temperature performance, followed by the low-temperature performance and the anti-fatigue performance.

\section{Conclusions}

The usage of liquid-based polymeric isocyanate (PRM) as a bitumen modifier shows huge potential both in actual application and environmental protection. PRM-modified bitumen was prepared with LH-70 and LH-90 base bitumen in this research. The thermooxidative and UV-aged bitumen samples were obtained by the RTFOT, PAV, and UV aging tests, respectively. The aging properties of bitumen were investigated by semi-empirical, rheological, MSCR, SENB, and LAS test methods. The aging mechanism was studied using FTIR and the thermal properties were studied using DSC test. The relationship of chemical composition and mechanical behaviors were also studied. The applicability of the indexes to the evaluation of the aging performance of PRM-modified bitumen was discussed. Based on the above work, some crucial conclusions are drawn as follows:

(1) The chemical investigations using the FTIR show that the thermal-oxidation aging and UV aging have a stronger influence on the formation of carbonyl structures than for the sulfoxide structures. The thermal-oxidation aging and UV aging can both lead to a decrease in the glass transition temperature.

(2) The evaluation of aging behaviors by physical tests shows that the susceptibility of PRM-modified bitumen to the thermal-oxidation aging and UV aging is different. The semi-empirical indexes (i.e., VAI, RPR, SPI) cannot accurately reflect the UV aging resistance of PRM-modified bitumen. There are no consistency results presented when using the semi-empirical aging index to evaluate the thermal-oxidation and UV aging resistance of PRM-modified bitumen.

(3) The thermal-oxidation aging and UV aging have a significant influence on the hightemperature performance, low-temperature performance, and anti-fatigue performance for PRM-modified bitumen. The general trends of performance degradation present consistent results with the rheological tests.

(4) The influence of thermal-oxidation and UV aging on the mechanical and chemical performance of PRM-90 is more obvious than those of PRM-70. The use of low-penetration-grade bitumen and ensuring an adequate reaction are beneficial to enhance the aging resistance of PRM-modified bitumen. Due to the effect of aging, the change of high-temperature performance of PRM-modified bitumen is great, followed by the low-temperature performance and the anti-fatigue performance. The mechanically relevant rheological aging index (CAI) and fracture energy index (FEI) are recommended to be used in the evaluation of aging properties.

In the future, the mechanism of aging and the effect of the modifier on the aging performance of PRM-modified bitumen will be further studied. Taking the SARA fractions of asphalt as the research objective, the experimental tests and theoretical analyses will be carried out from the perspective of mechanical and chemical properties. 
Author Contributions: Conceptualization, B.H., H.W., D.W. and M.O.; methodology, B.H. and D.W.; software, L.Z., P.L. and G.H.; validation, B.H., H.W. and D.W.; formal analysis, L.Z., S.Z. and P.L.; investigation, L.Z. and P.L.; resources, B.H. and D.W.; data curation, L.Z., P.L. and G.H.; writing —original draft preparation, L.Z., P.L., G.H. and S.Z.; writing-review and editing, B.H. and H.W.; visualization, B.H. and H.W.; supervision, B.H. and H.W.; project administration, B.H. and D.W.; funding acquisition, B.H., D.W. and M.O. All authors have read and agreed to the published version of the manuscript.

Funding: This research was funded by the National Natural Science Foundation of China (51908165), the German Research Foundation (DFG) under Grant No. OE 514/15-1 (459436571), the China Postdoctoral Science Foundation funded project (BX20180088), and the Heilongjiang Postdoctoral Fund (LBH-Z18083). The authors are solely responsible for the content.

Institutional Review Board Statement: Not applicable.

Informed Consent Statement: Not applicable.

Data Availability Statement: All data during the study appear in the submitted article.

Acknowledgments: Since the main works of this study were finished in Harbin Institute of Technology (HIT), the authors gratefully acknowledge the support of HIT.

Conflicts of Interest: The authors declare no conflict of interest.

\section{References}

1. Carreño Gómez, N.H.; Oeser, M. Investigation on the use of a novel chemical bitumen additive with reclaimed asphalt and at lower mix production and construction temperatures: A case study. Road Mater. Pavement Des. 2021, 22, S641-S661. [CrossRef]

2. Li, T.S.; Carreño Gómez, N.H.; Lu, G.Y.; Liang, D.; Oeser, M. Use of Polyurethane Precursor-Based Modifier as an Eco-Friendly Approach to Improve Performance of Asphalt. J. Transp. Eng. Part B Pavements 2021, 147, 04021031. [CrossRef]

3. Lu, X.; Isacsson, U. Effect of ageing on bitumen chemistry and rheology. Constr. Build. Mater. 2002, 16, 15-22. [CrossRef]

4. $\quad$ Li, Y.T.; Li, L.F.; Zhang, Y.; Zhao, S.F.; Xie, L.D.; Yao, S.D. Improving the aging resistance of styrene-butadiene-styrene tri-block copolymer and application in polymer-modified asphalt. J. Appl. Polym. Sci. 2010, 116, 754-761. [CrossRef]

5. Lesueur, D. The colloidal structure of bitumen: Consequences on the rheology and on the mechanisms of bitumen modification. Adv. Colloid Interface Sci. 2009, 145, 42-82. [CrossRef] [PubMed]

6. Siddiqui, M.N.; Ali, M.F. Investigation of chemical transformations by nmr and gpc during the laboratory aging of arabian asphalt. Fuel 1999, 78, 1407-1416. [CrossRef]

7. Ruan, Y.; Davison, R.R.; Glover, C.J. The effect of long-term oxidation on the rheological properties of polymer modified asphalts. Fuel 2003, 82, 1763-1773. [CrossRef]

8. Gawel, I.; Baginska, K. Effect of chemical nature on the susceptibility of asphalt to aging. Pet. Sci. Technol. 2004, 22, 1261-1271. [CrossRef]

9. Yu, J.Y.; Feng, P.C.; Zhang, H.L.; Wu, S.P. Effect of organo-montmorillonite on aging properties of asphalt. Constr. Build. Mater. 2009, 23, 2636-2640. [CrossRef]

10. Petersen, J.C.; Branthaver, J.F.; Robertson, R.E.; Harnsberger, P.M.; Duvall, J.J.; Ensley, E.K. Effects of physicochemical factors on asphalt oxidation kinetics. Transp. Res. Rec. 1993, 1391, 1-12.

11. Curtis, C.W.; Ensley, K.; Epps, J. Fundamental Properties of Asphalt-Aggregate Interactions Including Adhesion and Absorption. Strategic Highway Research Program, National Academy of Sciences. 1993. Available online: https://trid.trb.org/view.aspx?id= 386722 (accessed on 20 July 2021).

12. Cortizo, M.S.; Larsen, D.O.; Alessandrini, J.L. Effect of the thermal degradation of sbs copolymers during the ageing of modified asphalts. Polym. Degrad. Stab. 2004, 86, 275-282. [CrossRef]

13. Wang, S.; Wang, Q.; Li, S. Thermooxidative aging mechanism of crumb-rubber-modified asphalt. J. Appl. Polym. Sci. 2016, 133, 43323. [CrossRef]

14. Nie, Y.H.; Zhang, Y.L.; Yu, J.Y.; Kuang, D.L.; Zhang, X.P. Research on aging mechanism and recycling mechanism based on asphalt four components analysis. Appl. Mech. Mater. 2012, 204-208, 1659-1664. [CrossRef]

15. Xu, G.; Hao, W. Molecular dynamics study of oxidative aging effect on asphalt binder properties. Fuel 2017, 188, 1-10. [CrossRef]

16. Chen, A.; Liu, G.; Zhao, Y.; Li, J.; Pan, Y.; Zhou, J. Research on the aging and rejuvenation mechanisms of asphalt using atomic force microscopy. Constr. Build. Mater. 2018, 167, 177-184. [CrossRef]

17. Bahia, H.U.; Anderson, D.A. Glass transition behavior and physical hardening of asphalt binders (with discussion). J. Assoc. Asph. Paving Technol. 1993, 62, 93-129.

18. Hesp, S.A.M.; Iliuta, S.; Shirokoff, J.W. Reversible aging in asphalt binders. Energy Fuels 2007, 21, 1112-1121. [CrossRef]

19. Bele, A.; Merijs-Meri, R.; Bērzia, R.; Zicāns, J.; Ivanova, T. Effect of bio-oil on rheological and calorimetric properties of RTFOT aged bituminous compositions. Int. J. Pavement Res. Technol. 2020, 14, 537-542. 
20. Izquierdo, M.A.; Navarro, F.J.; Martínez-Boza, F.J.; Gallegos, C. Structure-Property relationships in the development of bituminous foams from PRM based prepolymers. Rheol. Acta 2014, 53, 123-131. [CrossRef]

21. Dong, Z.J.; Zhou, T.; Luan, H.; Williams, R.C.; Wang, P.; Leng, Z. Composite modification mechanism of blended bio-asphalt combining styrene-butadiene-styrene with crumb rubber: A sustainable and environmental-friendly solution for wastes. J. Clean. Prod. 2019, 214, 593-605. [CrossRef]

22. Liu, H.; Chen, Z.; Wang, W.; Wang, H.; Hao, P. Investigation of the rheological modification mechanism of crumb rubber modified asphalt (crma) containing tor additive. Constr. Build. Mater. 2014, 67, 225-233. [CrossRef]

23. Soenen, H.; Besamusca, J.; Hartmut, R. Laboratory investigation of bitumen based on round robin dsc and afm tests. Mater. Struct. 2014, 47, 1205-1220. [CrossRef]

24. Planche, J.P.; Claudy, P.M.; Létoffé, J.M.; Martin, D. Using thermal analysis methods to better understand asphalt rheology. Thermochim. Acta 1998, 324, 223-227. [CrossRef]

25. Hoare, T.R.; Hesp, S.A. Low-temperature fracture testing of asphalt binders: Regular and modified systems. Transp. Res. Rec. 2000, 1728, 36-42. [CrossRef]

26. Lei, Z.; Bahia, H.; Yi-qiu, T. Effect of bio-based and refined waste oil modifiers on low temperature performance of asphalt binders. Constr. Build. Mater. 2015, 86, 95-100. [CrossRef]

27. Wang, D.; Liu, Q.; Yang, Q.; Tovar, C.; Tan, Y.; Oeser, M. Thermal oxidative and ultraviolet ageing behaviour of nanomontmorillonite modified bitumen. Road Mater. Pavement Des. 2019, 22, 121-139. [CrossRef]

28. Wang, Y.; Wen, Y.; Zhao, K.; Chong, D.; Wong, A.S.T. Evolution and locational variation of asphalt binder aging in long-life hot-mix asphalt pavements. Constr. Build. Mater. 2014, 68, 172-182. [CrossRef]

29. Zeng, W.; Wu, S.; Wen, J.; Chen, Z. The temperature effects in aging index of asphalt during uv aging process. Constr. Build. Mater. 2015, 93, 1125-1131. [CrossRef]

30. Goodrich, J.L. Asphalt and polymer modified Asphalt properties related to the performance of Asphalt concrete mixes (with discussion). Assoc. Asph. Paving Technol. Proc. 1988, 57, 116-175.

31. Airey, G.D.; Brown, S.F. Rheological performance of aged polymer modified bitumens. J. Assoc. Asph. Paving Technol. 1998, 67, 66-100.

32. Dondi, G.; Mazzotta, F.; Simone, A.; Vignali, V.; Sangiorgi, C.; Lantieri, C. Evaluation of different short term aging procedures with neat, warm and modified binders. Constr. Build. Mater. 2016, 106, 282-289. [CrossRef]

33. Olard, F.; Di Benedetto, H. General "2s2p1d" model and relation between the linear viscoelastic behaviours of bituminous binders and mixes. Road Mater. Pavement Des. 2003, 4, 185-224.

34. Marasteanu, M.O.; Anderson, D.A. Improved model for bitumen rheological characterization. In Eurobitume workshop on performance related properties for bituminous binders. Brussels. Belg. Eur. Bitum. Assoc. 1999, 133, 1-4.

35. Cavalli, M.C.; Zaumanis, M.; Mazza, E.; Partl, M.N.; Poulikakos, L.D. Effect of ageing on the mechanical and chemical properties of binder from rap treated with bio-based rejuvenators. Compos. Part B Eng. 2018, 141, 174-181. [CrossRef] 